Math. Model. Nat. Phenom.

Vol. 6, No. 2, 2011, pp. 1-53

DOI: $10.1051 / \mathrm{mmnp} / 20116201$

\title{
Plant Growth and Development - Basic Knowledge and Current Views
}

\author{
V. Brukhin ${ }^{1}$ and N. Morozova ${ }^{2 *}$ \\ ${ }^{1}$ IBERS Department, University of Wales, Aberystwyth, United Kingdom \\ ${ }^{2}$ 1FRE CNRS 3239, Institute André Lwoff, Villejuif, France
}

\begin{abstract}
One of the most intriguing questions in life science is how living organisms develop and maintain their predominant form and shape via the cascade of the processes of differentiation starting from the single cell. Mathematical modeling of these developmental processes could be a very important tool to properly describe the complex processes of evolution and geometry of morphogenesis in time and space. Here, we summarize the most important biological knowledge on plant development, exploring the different layers of investigation in developmental processes such as plant morphology, genetics, plant physiology, molecular biology and epigenetics. As knowledge on the fundamentals of plant embryogenesis, growth and development is constantly improving, we gather here the latest data on genetic, molecular and hormonal regulation of plant development together with the basic background knowledge. Special emphasis is placed on the regulation of cell cycle progression, on the role of the signal molecules phytohormones in plant development and on the details of plant meristems (loci containing plant stem cells) function. We also explore several proposed biological models regarding regulating plant development. The information presented here could be used as a basis for mathematical modeling and computer simulation of developmental processes in plants.
\end{abstract}

Key words: plant growth, development, auxin, models

AMS subject classification: $92 \mathrm{C} 80$

*Corresponding author. E-mail: morozova@vjf.cnrs.fr 


\section{Overview of plant growth and development}

Plant growth could be defined as the increasing of plant volume and/or mass with or without formation of new structures such as organs, tissues, cells or cell organelles. Growth is usually associated with development (cell and tissue specialization) and reproduction (production of new individuals).

In the scientific literature there are several different criteria for the determination of plant growth rates, which are sometimes contradictory to each other: plant height or width, mass (wet or dry), cell number, protein or other essential substances content. Examples of such contradiction in growth rate determination are the processes in quiescent plants and plants organs which cause new structures to form without changes in volume and dry mass and the process of germination, following by volume increasing with decreasing of dry mass. Cell division in early stages of embryogenesis lead to 200-fold increase in cell numbers, could, in some cases, occur without changing in volume of the whole embryo and without changing in its mass.

There are several striking differences in the details of the growth process between multicellular plants and animals. The main difference is that animals are determinate in their growth pattern. They need to reach a certain size before they are mature and start to reproduce. After a certain age animals are not able to grow and reproduce. Conversely, plants have and indeterminate growth pattern being able to grow and to produce new cells during their entire lifespan. To some extent this could be considered as immortal as they are able to reproduce by both vegetative and generative ways. Whilst normal growth in animals is considered to be more the result of an increase in cell numbers and much less the result of cell enlargement, the process of plant growth is largely the result of both increasing of cell numbers and its' size.

Normally, the process of the growth of each cell undergoes three different phases: cell division, increase in volume and differentiation. However, in some cases one of these phases could be skipped. Each phase has its own specific molecular and physiological characteristics although at some stages of development two or even three phases can occur simultaneously.

The process of cell division (also called cell cycle progression) is very similar in both plants and animals, however, the increase in volume phase may occur quite differently between plants and animals. This is due to the fact that plant cells have vacuoles that allow the size of the cell to increase drastically and quickly. In addition, plant cells have cellulose walls that restrain cell growth and it is this feature that has the major impact on the growth and the size characteristics of the cell.

The final stage, cell differentiation, plays a very important role in plant development and morphogenesis as it gives rise to the formation of new types of cells, tissues and organs. During this process two daughter cells are formed after the division of a maternal cell and they start to undergo different molecular processes. As the result of this cells accumulate different molecules and substances leading to the formation of different tissues or structures.

In multicellular plants there are distinct zones where cell division occurs called meristems, inside which a self-renewing population of plant stem cells is located. These cells hold the unique property of totipotency, which means the ability of a cell to divide and produce all cell types of a growing organism. The shoot apical meristem (SAM) and the root apical meristem (RAM) 
produce all the primary organs and give the main blueprint for the development of the rest of the plant. As long as the plant maintains a group of these meristematic cells in the vegetative state, shoot growth and development is indeterminate and the plant has the potential for different pathways in its pattern formation. The SAM of the main shoot and the RAM of the main root are formed embryonically, whereas the other meristems in plants are formed post-embryonically.

The shoot apical meristem (SAM) is the main plant meristem as it is located at the growing tip of the main shoot and is a source of all above-ground plant organs. Cells at the SAM top serve as stem cells to the surrounding peripheral region, where they proliferate rapidly and are incorporated into differentiating leaf or flower primordia (commencements of new plant organs). Primordia of leaves and flowers are initiated in SAM at the rate of one per every time interval, called a plastochron, forming a unit of plant development, called a module. There is a meristematic locus derived from SAM inside each module and this locus has the potential to develop into axillary shoot meristems under certain conditions or signals leading to the production of new plant organs. However, without specific circumstances this meristematic locus remains largely dormant.

Although the form and shape of each plant organ is precisely defined for each plant species and each plant grows according to a certain set of rules, the entire plant architecture is not strictly determined in most cases as the processes of new root, shoot and flower formation is generally indeterminate.

This plant plasticity is possibly due to the presence of axillary meristems inside all plant modules as well as the high level of totipotency of the differentiated plant cells. This allows them, under specific external signaling, to undergo dedifferentiation with the formation of new meristematic locus (adventious meristems) with the capability of forming new organs immediately. The process of cell dedifferentiation (i.e. the withdrawal of a given cell from its differentiated state into a 'stem cell' like state that confers totipotency) is inevitably associated with re-entry of this cell into the cell cycle (cell proliferation) (Bloom, 1937, Odelberg, 2002, Grafi, 2004).

Without additional meristem formation the regular development of each plant represents the growth of repeating units (modules, or phytomers) formed in SAM as a result of the reiterations of leaf primordia formation. A typical phytomer consists of a node, a subtending internode, a leaf developing at the node sites and an axillary bud (also called lateral buds) located at the base of the leaf (Fig.1). Different phytomers within the same plant may vary in internodes size, shape etc. depending on their position on the shoot. For example, the internodes in the apical (terminal) meristem are very short so that developing leaves above the SAM act as protection for them (Fig. 1). However, each one phytomer develops during the time interval of one plastochron (Steeves and Sussex, 1989). All shoot branches of the plant are then derived from axillary meristems that subsequently function as a shoot apical meristem (SAM) for the new shoots produced from the axillary (lateral) bud. Variation in branching pattern is one of the main factors contributing to the vast diversity in architecture found amongst plants. This variability depends on axillary meristems activity and is influenced by three main factors: patterns of axillary shoot meristem initiation, lateral shoot bud development and lateral shoot branch outgrowth.

In addition to the formation of branches (new shoots), the axillary buds can also produce other plant organs, e.g. leaves or flowers or in some plants terminal structures such as prickles, thorns and tendrils. Generally the axillary bud formation and activity for the given plant species is genet- 


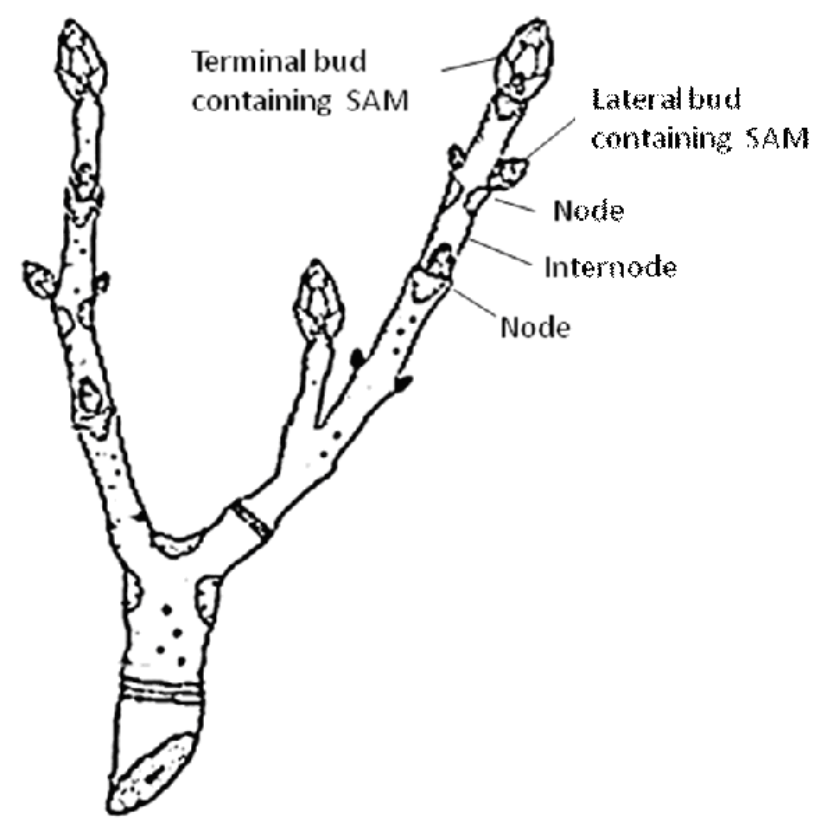

Figure 1: Plant phytomer (module) structure.

ically predetermined resulting in the given architecture of a plant. For example, there are plants with single, branched or multiple shoots or with single or multiple flowers per one shoot patterns. However, under different conditions axillary bud activity can also be indeterminate leading to considerable variability in branching pattern. This can strongly influence the final shape and appearance of the plant as each bud can in turn produce indeterminate (vegetative) or determinate (flower) structures.

Nevertheless, in most cases the main features of plant architecture are predetermined and each plant species has its own phyllotaxis, i.e. the spatial arrangement of plant organs around the shoot axis. Phylotaxis is established in the SAM when leaf primordia are formed in the certain order and at determined pattern (Jean, 1994). For example, leaf phylotaxis pattern can be spiral, alternating (distichous) or decussate.

All above-ground primary meristems (SAMs) in turn produce two secondary meristem types that surround the stem of a plant and lead to the lateral growth of the plant i.e. vascular cambium (which produces xylem and phloem) and cork cambium (which gives rise to the bark of a tree). Sometimes secondary meristems are also called "lateral meristems", which should not be confused with "lateral (axillary) bud" on the shoot, as these are two completely different issues!

All important processes of plant growth, metabolism and morphogenesis are regulated by signal molecules produced within the plant and named plant hormones (or phytohormones). These are capable of influencing cellular processes at extremely low concentrations in the cell and are produced at close or distal locations of the targeted cell (Osborne et al., 2005). Hormones are necessary for normal plant development as they are involved in determining the shape of the plant, affect seed growth, time of flowering, senescence of leaves and fruits and many others processes. 
Thus, without the proper production and distribution of plant hormones plants would be mostly a mass of undifferentiated cells. Certain concentrations and ratio of plant hormones in plant cell culture can cause formation of different organs such as roots, flowers or even somatic embryos from undifferentiated cells. Plants, unlike animals, do not have specific organs (glands) that produce and secrete hormones. The three phytohormones, auxins, cytokinins and gibberellins, are considered to be the most positive regulators of growth and development, whereas, ABA and Ethylene are considered to be growth the inhibitors or suppressors. Jasmonic acid is currently suggested as the sixth phytohormone although its role is not as pronounced as the role of the other five classes.

Indole-3-acetic acid (IAA) is the most common type of auxin found in plants and is produced predominately in the shoot apical meristem (SAM), but it can be also be synthesized in roots and other plant structures. Auxins are hormones that positively influence cell elongation by altering cell wall plasticity, bud formation, root initiation as well as lateral and adventitious root development, flower initiation and specific protein synthesis during seed formation. Auxin is involved in the phenomenon known as apical domination which means the suppression in the formation and/or growth of additional SAMs in axillary meristems. Apical domination is implemented by the activity of the dominant SAM of the main branch. Auxins can also promote the production of other hormones. Along with other hormones, mostly cytokinins, auxins control the development of stems, roots, flowers and fruits. The interesting feature of auxin production is that it is regulated by light. Auxin concentrations decrease in the presence of light and increase in darkness.

Cytokinins are a group of hormones that influence cell division and, in combination with auxin, promote shoot formation. Previously cytokinins were known simply as kinins when first isolated from yeast cells. Cytokinins also help to delay senescence or the aging of tissues and in coordination with auxins, they control the development of stems, roots, flowers and fruits.

Abscisic acid (ABA) is found in high concentrations in newly-abscised or freshly-fallen leaves and acts as an inhibitor of bud growth causing seed and bud dormancy. It accumulates within seeds during fruit maturation, preventing seed germination within the fruit or seed germination before winter. In the absence of ABA, buds and seeds would start to germinate during warm periods in winter and subsequently lead to death of the germinating seedling once colder weather occurs. ABA is also involved in plant protection from different kinds of stresses. ABA has complex interactions and act together with other phytohormones for example when ABA levels decrease and gibberellin levels increase growth is promoted.

Ethylene is a hormone produced by plant cells in a gaseous form as a result of the breakdown of methionine. As ethylene has very limited solubility in water it cannot accumulate within the cells and thus quickly diffuses out of the cell. Its effectiveness as a plant hormone is dependent on its rate of production versus its rate of diffusing into the atmosphere. Ethylene affects fruit-ripening in a way that when seeds are mature, ethylene production increases, resulting in a climacteric event just before seed dispersal. Some data suggest that ethylene is produced at a faster rate in rapidly growing and dividing cells, especially in darkness. Ethylene also affects the stem natural geotropic response. The nuclear protein ETHYLENE INSENSITIVE2 (EIN2) is regulated by ethylene production and regulates other hormones including ABA (Wang et al., 2007).

Gibberellins (GA) play a major role in seed germination, affecting the production of enzymes that mobilize nutritive substances needed for growing cells. GA acts through the modulating of 
chromosome transcription. In seeds there is a layer of cells called the aleurone that wrap around the endosperm. During seed germination the seedling produces GA that is transported to the aleurone layer which responds by producing enzymes that break down stored food reserves within the endosperm. These are then utilized by the growing seedling. GAs produce bolting of rosette-forming plants, increasing internodal length and can promote flowering, cellular division, and in growth after germination. Gibberellins also reverse the inhibition of shoot growth and dormancy induced by ABA.

Jasmonate class of plant hormones are derivatives of jasmonic acid (JA). The major function of jasmonic acid is to regulate growth inhibition, senescence and leaf abscission. It has an important role in response to wounding of plants and in insect resistance, during which the plant releases JA to inhibit the ability of insects to digest proteins. JA can also be converted into a number of derivatives such as esters (e.g. methyl jasmonate) and may also be conjugated to amino acids.

Although all hormones are important for the normal development of the plant most of the recent studies show evidence that auxin plays an exceptional role in the formation of plant organs. However, some studies report that the interplay between auxin and cytokinins is the most important factor in plant development, whereas others state that the interplay between auxin, jasmonic acid and gibberelin as being the most important; and finally some investigators report that the major regulation of plant development is solely due to auxins (see paragraph 5 for details and references).

In addition to hormonal regulation, plant growth is highly influenced by environmental factors. Internal control systems interact with the external environmental stimuli through the signal transduction chains activating or suppressing corresponding transcription factors and genes. Epigenetic control of cells facilitates differential gene expression through DNA methylation, miRNAand siRNA-based systems, and histon modification, mechanisms that switch off and on gene when necessary. Epigenetic mechanisms thereby mediate developmental progression and also resilence to accommodate for change.

Plants take on mineral elements, first of all nitrogen, phosphorus and microelements from the soil. These elements are needed for plant body construction as well as for the biochemical reactions being important constituents of many enzymes and co-factors. Lack of these mineral elements leads to the impairment of plant growth reducing the vigor and may result in plant death. Cell expansion is controlled by turgor, which depends on water and osmotic pressure. Deficit in the water supply limits plant cell elongation through the reduction of cell turgor.

Photosynthesis is the process by which plants convert carbon dioxide and water into sugar using the energy of the sunlight and release oxygen. Photosynthesis is tightly associated with the green pigment chlorophyll that is compartmentalized within the cell organelles called chloroplasts. Some of the light energy gathered by chlorophyll is stored in the form of adenosine triphosphate (ATP)commonly known as the cell's universal "currency" which is used as the "fuel" for all biochemical reactions. Thus, photosynthesis is the source of the carbon in all the organic compounds within organisms (e.g. carbohydrates) and these are required by the cell to produce osmotic pressure to retain water as well as for energetic and constructive functions. Light is the crucial factor for photosynthesis and therefore is very important in the control of plant growth. 


\section{Plant embryogenesis}

Embryogenesis is the first stage of the development of a new organism from its first cell named zygote, which appears as a result of the sexual fertilization, i.e. fusion of the egg cell and the sperm cell. In flowering plants embryo development normally occurs after a process known as double fertilization during which one haploid sperm cell nucleus fuses with the haploid egg cell nucleus to produce a diploid zygote that initiates the development of the embryo, while the other fuses with a di-haploid central cell nucleus, initiating the development of endosperm, providing nourishment for the developing embryo. After fertilization the zygote enters a period of quiescence, which may last from several minutes to several months in different plant species after which time the zygote then undergoes several consecutive divisions resulting in a mature embryo.

In animals the body plan and all organ tissues are formed during embryogenesis, the plant embryos are very simple and most of the organs are formed post-embryonically from meristems. Plant embryogenesis is usually divided into the three phases: The first involves the establishment of polarity and lasts up to the globular embryo stage. In this stage the so called proembryo (from zygote up to the globular embryo) has a radial symmetry. In the second stage, morphogenetic events in the embryo form basic cellular pattern for further development, the primary tissue layers and also establishment of the regions of meristematic tissue development take place. And the third phase is the postembryonic one, which involves events that prepare the embryo for desiccation, dormancy and germination. Mature plant embryos have a bilateral symmetry and consist of the main axis (cotyledons, epicotyl, shoot apical meristem (SAM), hypocotyl, root apical meristem (RAM)). Monocots are plants that have only one cotyledon while dicots have two.

The critical cell numbers after which proembryo enters in the first step of differentiation, i.e. formation of embryoderm, varies in different plant families, e.g. there are around 500 cells for Nelumbo nucifera (Nelumbonacea) (Batygina and Vasilyeva, 2003) compared with only 16 cells in Arabidopsis thaliana (Brassicaceae) (Howell, 2000).

At the early stages of angiosperms embryogenesis embryos have radial symmetry that is later replaced by a bilateral one. The question of the genetic control of the transformation of symmetry is still under discussion. There is data, confirming the role of polar auxin transport in this process, showing that application of auxin transport inhibitors cause formation of aberrant embryos (Geldner et al., 2001,2003,2004).

Here we consider the most common Capsella-type embryogenesis typical for the dicotyledonous model plant Arabidopsis thaliana from the Brassicaceae family (Fig. 2).

The establishment of polarity is one of the most fundamental steps in the organization of the body plan. Polarity starts from the initial process of fertilization, when following the fusion of the egg cell and the sperm cell the zygote nucleus migrates from the central part to the chalazal pole of the cell. After first asymmetric division of the zygote, a small apical cell, which later becomes the embryo and a large basal cell, the progenitor of the suspensor, are formed (Fig. 2A a-b). First and several consecutive divisions of the apical cell produce the proembryo, while the basal cell which is attached to the maternal tissue undergoes several longitudinal divisions producing the suspensor, a structure that provides nutrients from the endosperm to the growing embryo and anchor it to the maternal tissue. The suspensor consists of the large vacuolated cells containing small nuclei. In the 
a

b c d

e

f

g

$\mathrm{h}$

i
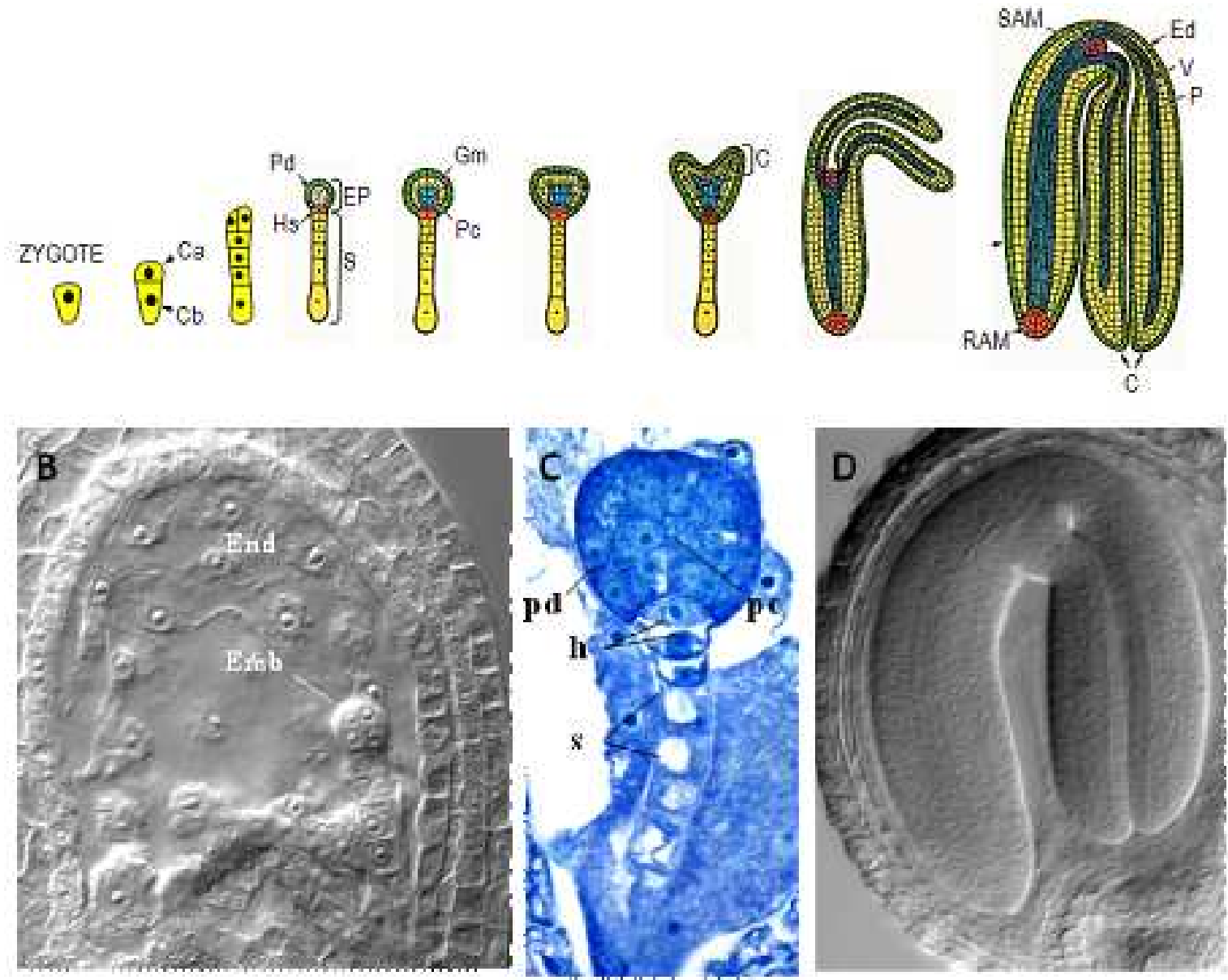

Figure 2: Normal (sexual) embryogenesis (embryogenesis in Arabidopsis) A - Schematic representation of the main embryogenic stages. a - zygote, b - two celled embryo, c- proembryo at the quadrant stage, d- early globular proembryo, e- globular embryo, $\mathrm{f}$ - embryo at the transition form, g- heart shaped embryo, h- embryo at the bent cotyledon stage, i- mature embryo (walking stick stage). Ca- apical cell, Cb- basal cell, Pd - protoderm, Hs- hypophytsis, PE- peoper embryo, S - suspensor, Gm - ground meristem, Pc- procambium, C- cotyledon, P- procambial tissue, V- vascular tissue. B,C,D-Cleared seed under light microscope with DIC (differential interference contrast). B - Embryo at the quadrant stage. Emb- embryo, End- endosperm C - Early heart shaped embryo. Toluidine blue-stained section under light microscope. $\mathrm{H}$ - derivatives of hypophyseal cell; pc, procambial cells; pd, protoderm; s, suspensor. D - Mature walking stick cotyledon embryo. 
case of Arabidospsis the mature suspensor has eight cells and the uppermost cell of the suspensor is called hypophysis. The latter takes part in the lateral root cap and RAM formation and is also thought to be involved in auxin synthesis and therefore in the maintenance of polarity along the main axis of the growing embryo. Interestingly, the suspensor has no plasmodesmata (microscopic channels traversing cell wall enabling cell communication and molecular transport) connection to the cells of the embryo but has elaborated cell wall outgrowths characteristic of haustorium-like transfer cells.

The first division of the apical cell is transverse. Then transverse divisions are alternated with the longitudinal and thus proembryo passes thorugh the stages of two- (Fig 2A c), four- (quadrant Fig. 2B), eight- (octant), 16-celled proembryos and so on up to the globular stage (Fig. 2A-d, -e) when the beginning of the histogenesis, i.e. differentiation of the embryonic cells, takes place. At the globular stage the embryo develops radial patterning with the outer layer of cells differentiating into the protoderm (Pd). Two layers of inner cells in the globular embryo have distinct developmental fates: ground meristem $(\mathrm{Gm})$ cells accumulate proteins and oils and give rise to the cortical parenchyma and procambial cells $(\mathrm{Pc})$ that are the progenitors of the provascular cells. Cells in the different layers are distinguished by the division patterns and by their morphological appearance. At the late globular stage subepidermal cells start anticlinal divisions producing cotyledon initials (first embryonic leaves), so the embryo enters in early heart-shaped (or transition) stage (Fig. 2A$\mathrm{f}-\mathrm{g}, \mathrm{C}$ ). Later on cotyledons keep growing with shoot apical meristem differentiating inbetween the cotyledons. The lower layer of the embryo produces the hypocotyl and root meristem. From the heart stage on the embryo acquires bilateral symmetry. Further formation of the organs gives the shape to the embryo and corresponding stage name: heart, torpedo and walking stick (bent cotyledons) (Fig.2 A g-i, C, D). Provascular and procambial tissues differentiate from the heart-shaped stage onward.

Plant embryos are relatively simple in morphology, however, a great number of genes are expressed at different stages throughout embryogenesis. For example, in Arabidopsis at least 4000 genes are essential for normal embryogenesis to occur. According to the concept of pattern formation in animal and plant embryos, embryos are subdivided into distinct segments or modules each of which has its own polarity and interacts with other segments in a certain way. Only a handful of genes are master regulators, i.e. involved in pattern formation and control basic processes of the embryo body plan. According to Jürgens (1991) only around 1\% of all the genes essential for plant embryogenesis are master regulators. One of the first genes that is selectively expressed after the first division of the zygote only in the apical cell is the ARABIDOPSIS THALIANA MERISTEM LAYER1 (ATML1) gene (Lu et al. 1996). Several other key genes affect patterning in Arabidopsis.

A mutation in the GNOM gene leads to the impairment of the embryo in establishing apicalbasal polarity (Mayer et al. 1993). The first division of the zygote in gnom mutants is not asymmetric so it produces apical and basal cells of almost equal sizes. Embryos in gnom mutants look nearly round leading to the death of the embryo.

A mutation in the MONOPTEROS gene causes deletion of the basal region and lack of the hypocotyl and RAM. In monopteros mutants only cells of the upper tier of the proembryo develop, while the cells of the lower tier remain isodiametric and don't form linear files (Berleth and Jürgens, 1993). In the momopteros cotyledons show less positional symmetry than wild type embryo which 
indicates that basal region of the proembryo apparently participates in the establishment of the hormone gradients. It has been shown that although momopteros mutants are not able to organise basal tier they don't lose ability to form roots under special treatment (Berleth and Jürgens, 1993). Thus, MONOPTEROS affects phenotype early in embryo development, although later than gnom.

The GURKE gene controls the formation of the central and apical domain of the developing embryo. Defects in gurke mutants show a distinct phenotype at the early heart stage during embryo transition from radial to bilateral symmetry. Impaired GURKE alleles result in the failure of cotyledon formation due to misorientation and delay of the divisions in cells destined to be cotyledon promordia.(Torres-Ruitz et al., 1996).

Another type of embryo pattern genes are the ones involved in the establishment of the radial axis. Disruption of the gene KNOLLE results in the defects of the radial symmetry. konlle mutants show evident defects at the early globular stage followed by lack of distinct epidermis, which was disrupted and misorientated. Cloning and identification of the KNOLLE function revealed that the gene encodes the protein apparently involved in plasma membrane targets for secretory vesicles (Lukowitz et al., 1996).

Cell lineages in embryos occur according to their presumptive function at certain spatial and temporal patterns. Embryo development is orchestrated by certain master regulatory genes followed by epistatic action of numerous smaller player genes.

Construction of an embryo cell fate map was performed by Poethig et al. (1986) for maize (monocot plant) and by Scheres et al. (1994) for Arabidopsis (dicot plant) using transgene markers. Scheres et al. (1994) followed the fate of the cells in heart-shaped embryos focusing in root and hypocotyl cell lineages. An important observation was that the sector boundaries were not as defined as the morphological boundaries. This indicates that cell lineages correlate with the body plan only generally but not exactly.

A peculiar feature of plants unlike that of animals is that plants can also reproduce in an asexual or vegetative way, i.e. capacity to reproduction from somatic tissues without preceding gamete fusion. This is due to the capacity of a high level of totipotency in plant cells. This includes somatic embryogenesis,apomixis and vegetative propagation.

Somatic embryogenesis is the developmental pathway by which a conventional somatic cell or an unfertilized gametic cell develops into an embryo-like structure resembling a typical bipolar zygotic embryo (reviewed by Jimenez, 2001). Somatic embryoes of dicotyledons pass through the same developmental stages as zygotic counterpart, i.e. through the globular, heart and torpedo stages, however, somatic embryos do not produce suspensors in the somatic tissues. Since the middle of the 20th century somatic embryogenesis was successfully induced and maintained towards the adult plant formation in plant cell culture experiments (cell suspension cultures or callus cultures on the foliar surfaces) for most plant species. Although the majority of plant species can propagate via somatic embryogenesis in vitro, only a few species such as those in the families of Crassulaceae, or the Citrus genus normally form somatic embryos in vivo. For example, in Bryophyllum (Yarbrough, 1932; Batygina, 2006) and in Malaxis (Taylor 1967), somatic cells in the leaf margin normally undergo asexual embryogenesis by forming adventitious buds.

Another example of in vivo somatic embryognesis occurs in the genus Paeonia, where zygotes do not directly produce regular dicotyledonous sexual embryos, but instead form ceonocitic-cell 
A.

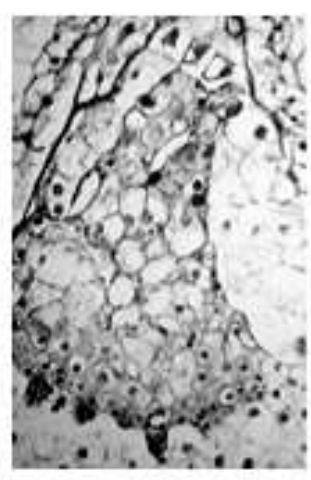

B
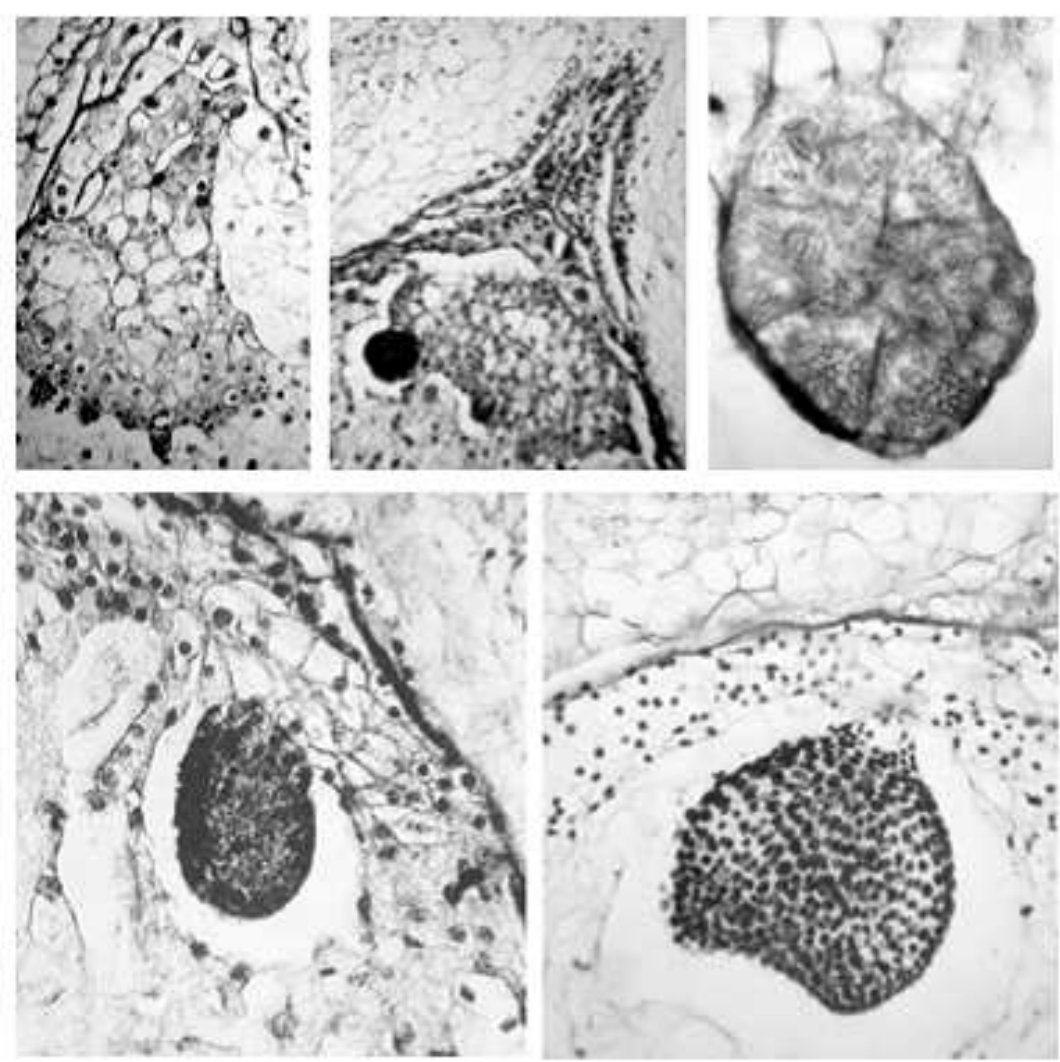

D

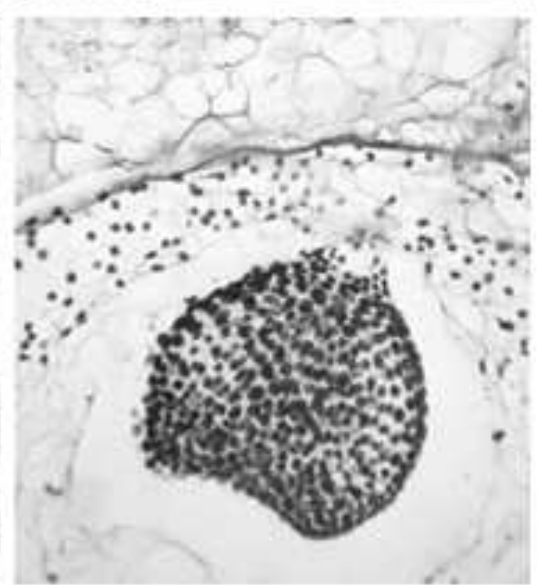

E

Figure 3: Somatic (asexual) embryogenesis (embryogenesis in Paeonia). Seed sections stained with light green under light microscope. A - Initiation of the somatic embryos at the coenociticcell proembryo. B - One dominating somatic embryo still attached to the shrunk coenocitic-cell proembryo. C - Survived somatic embryo enters globular stage. D - Globular stage of somatic embryo and remnants of the coenocitic-cell proembryo. E - Somatic embryo at the heart shape stage.

proembryos. After producing approximately 1500 nuclei, these proembryos initiate several other somatic embryos on their surface (Fig 3A, B). In the course of further embryogenesis somatic embryos continue developing while proembryos gradually shrink and become eliminated. Somatic embryos pass through the stages of globular (Fig 3C, D), heart (Fig 3E) and torpedo. These are typical for dicotyledonous embryos. Although several somatic embryos are formed on the surface of the proembryo, only one of them survives and becomes viable (Brukhin, 1993; Brukhin and Batygina 1994) (Fig 3B-E).

In general, the process of somatic embryogenesis can be divided into two phases: induction and expression. During the induction phase, differentiated somatic cells acquire embryogenic compe- 
tence and proliferate as embryogenic cells. Drastic alterations to existing gene expression patterns and developmental programs need to occur before a cell can begin embryogenic development. The cell must dedifferentiate, acquire embryonic competence, become embryogenically induced and become determined. These stages do not necessarily happen in a predetermined order, as in some cases, acquisition of competence, induction and division can occur simultaneously. Somatic embryogenesis in vitro is also an excellent model for studying the theory of plant embryogenesis, determining gene expression and measure substance accumulation at different stages of embryogenesis.

In some plants, like in the genera Taraxacum and Poa, seeds can be produced by a developmental program without sexual fertilization in a process called apomixis. There are several types of apomixis which have been observed in nature in different plant species. However, the most common classes observed are based on three different mechanisms, i.e. diplospory, apospory and adventitious embryony (Koltunow, 1993). In diplospory, gametophyte (embryo sac) arises from megaspore mother cell that failed to execute reductional division. Thus, all cells in the diplosporic embryo sac are unreduced and diploid egg cell gives rise to an embryo without fertilization. In apospory an embryo sac is formed from diploid somatic cell of the nucellus from which the embryo derives. Both diplosporic and aposporic apomicts are referred to as gametophytic apomicts, since in both cases production of a gametopyte takes place. There is another form of apomixis called sporophytic apomixis, when nucellar cells or cells of integuments (precursors of seed coats) form adventitious embryos similar to the way of somatic embryo formation.

In total more than 400 plant species can reproduce apomictically under natural conditions. Apomixis could be considered as a phenomenon of natural plant cloning and might play very important role in the fixation of useful traits for plant propagation.

Another type of asexual reproduction is simply through vegetatives structures. This is known as vegetative reproduction or propagation. By this process a new plant is produced without the production of seeds or spores. Vegetative reproduction is a type of clonal propagation. It involves only vegetative structures, i.e. roots, stems, leaves or their structural modifications like scaly bulbs, corms and stolons (stem modifications). Some plants like thistles and most bamboo species spread underground stems that produce new plants distributed at considerable distances from the original plant. The leaves (or modified leaves-such as tendrils) of some plants, e.g. strawberry, produce buds at their edges which then develop into miniature plants that fall off and take roots. This regenerative ability of plants is exploited in agriculture and horticulture through such techniques as the rooting of cuttings and the grafting and budding of fruit trees. The same is true for cutting of plants (such as the common potato) into pieces that are then planted separately, each with a bud ("eye"); and for numerous other techniques. The vegetative propagation of economically important and useful plants is now so widespread that most modern horticultural varieties are only reproduced through cloning.

Most of these cases of asexual and vegetative reproduction raise from the possibility of differentiated plant cells to undergo dedifferentiation and then produce meristems, or else, to behave like stem cells. 


\section{Plant meristems and stem cells are perpetually embryonic cells}

Mersitems can be simply defined as the "growing points" of plants (Sinnott, 1938). Compared to animals, plants have rather rigid structures being unable to move and to easily enlarge their cells due to presence of the thick cell wall. Therefore in order to be plastic plants have evolutionary acquired localized groups of undifferentiated cells where cell multiplication occurs, which are called meristems. The meristem is the strategic point where the fate of plant body development is primarily decided (Sinnott 1938).

Meristems are regions containing undifferentiated (meristematic) cells where cell proliferation takes place. Meristems are the progenitors of all plant tissues and organs from the very embryo onward during the entire lifespan of an individual.

Although due to the high level of totipotency differentiated plant cells are able to undergo dedifferentiation under many circumstances and start to behave as meristem cells, divide or produce cells of different types, in normal plant development this is the cell division in the meristems that required to provide new cells for expansion and differentiation of tissues and initiation of new organs, providing the basic structure of the plant body.

In higher plants all postembryonic development occurs due to the activity of apical meristems. During embryogenesis higher plants generate two different apical meristems, the shoot apical meristem (SAM), responsible for production of all aboveground plant organs stems, leaves and flowers, and the root apical meristem (RAM), producing cells of the primary and lateral root system. Meristematic cells are analogous in function to stem cells in animals, they are completely undifferentiated (or incompletely in some peripheral zones of meristem), and are capable of continued cellular division. Meristematic cells are different from other cells morphologically as they are small in size, contain smaller vacuoles, their cytoplasm does not contain differentiated plastids (chloroplasts or chromoplasts) and their cell wall is a very thin primary layer. Meristematic cells are packed closely together without intercellular cavities.

\subsection{Different types of meristems and their classification}

According to the place of localization in a plant and to the specific features of growing behavior all meristems can be divided into the following groups:

Apical meristems - the main group of plant meristems, located at the end of plant growing tips of the soot, i.e. shoot apical meristem (SAM) and of the root, i.e. root apical meristem (RAM).

Axillary meristems - at the axils of leaves (can form apical meristems under appropriate conditions). Intercalary meristem - on the stems at the base of nodes (only in monocotyledons plants).

Basal meristem - at the base of growing leaves, and also in roots in the region of transition between the meristem and the elongation zone, where the lateral root positioning takes place.

Adventitious meristems - potentially in all differentiated tissues of plant under specific conditions, emerging as a result of cell dedifferentiation followed by formation of the meristematic locus, with capability to immediate formation of new organs.

Apical meristems give rise to the three kinds of so-called primary meristems: 
1. Protoderm located around the outside of the stem forming the epidermis.

2. Procambium located just inside of the protoderm giving rise to the primary xylem and primary phloem. It also produces the vascular cambium as a secondary meristem.

3. Ground meristem gives rise to the pith. It produces the cork cambium, another secondary meristem.

The primary meristems produce two types of the secondary (lateral) meristems, which surround the stem of a plant and cause it to grow in girth: Vascular cambium and Cork cambium.

\subsection{The meristem structure}

Externally the apexes or growing tips of different plants vary greatly in their size and shape and in the pattern in which leaf primordia are formed. However, the internal structural organization of most angiosperm apexes differs relatively little. Cytohistochemical studies of sectioned meristems from various angiosperms indicate that different meristems of the vegetative shoot share a number of structural features.

Apical meristems are very small, compared to the lateral meristems, and differs from the latter in shape. Initialy, the organisation of the shoot and root apical meristems in higher plants were identified morphologically and later by molecular biological research. Together with common features shoot and root apical meristems have specific features due to their functions.

Shoot apical meristems (SAM) is a main plant meristem as it is the source of all above-ground plant organs. Cells at the SAM top serve as stem cells producing daughter cells to the surrounding region where they start to proliferate rapidly and next are involved into differentiation resulting in producing leaf or flower primordial. The meristem structure has three clonally distinct layers of cells (Fig.4). The cells of the outermost (epidermal) layer of the shoot meristem (L1 in red) undergo anticlinal cell divisions (e.g. perpendicular to the SAM surface), in the cells of the second (subepidermal) layer (L2 in yellow) divisions are orientated less anticlinal and in the innermost layer (L3- grey) cell divisions take place in various planes, resulting in growth in all directions, giving rise to the rest of the meristem (Fig. 4A) (Byrne et al., 2003).

In general the outermost layer (L1 only, or L1and L2 layers together) is called tunica while the innermost layers are the corpus. In monocots, the tunica determines the physical characteristics of the leaf edge and margin. In dicots layer two of the corpus determines the characteristics of the edge of the leaf. The corpus and tunica play a critical role in the plant physical appearance as all plant cells are formed from the meristems.

From the functional point of view, three distinct zones can be specified within apical meristem (Fig. 4): 1 - Central zone 2 - Peripheral zone 3 - Rib zone.

The central zone at the top of the meristem is a small group of slowly dividing cells acting as stem cells with the main function to maintain the pool of themselves and to replace the cells of the peripheral zone, which are consumed during the formation of the lateral organs. Lateral organs are produced from the cells of peripheral zone, whereas cells from the rib zone contribute to the bulk of the stem. The proliferation and growth rates of the central zone differ considerably from those at the periphery of meristem and at rib zone. 


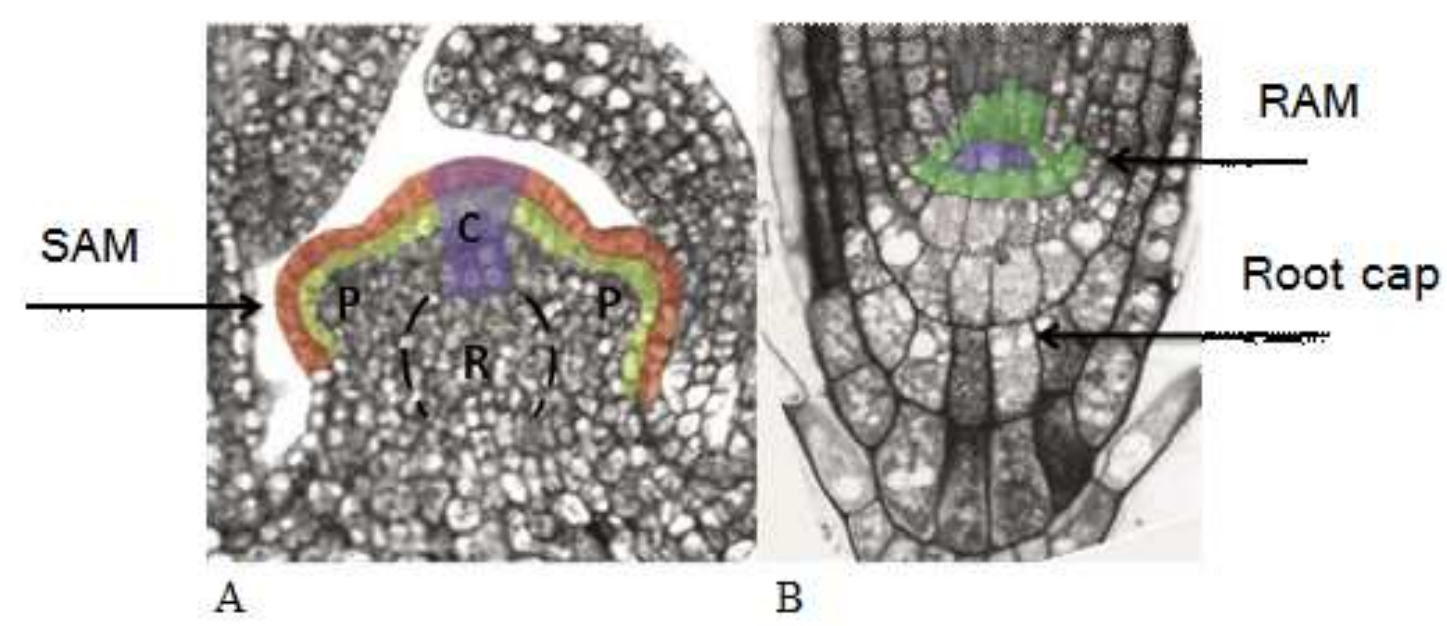

Figure 4: Shoot and Root apical meristems. A. The layered structure of the shoot apical meristem (SAM): the outermost layer (L1) is shown in red, the second layer (L2)- in yellow, the third (L3)-in gray; and functional zones of the apical meristem: C - Central zone (marked in blue),P - Peripheral zone, R - Rib zone. B. The root apical meristem (RAM) is subterminal, but like SAM has a layered structure. A center consists of slowly dividing cells (the quiescent center QC, shown in blue) surrounded by the initials for individual tissues (shown in green). Published with the permission of the Current Opinion in Genes \& Development 2003, 13: 551-557.

Floral meristem. When plants begin the developmental process known as flowering, the switch from vegetative growth to generative growth occurs within the shoot apical meristem, and the shoot apical meristem is transformed into an inflorescence meristem which goes on into the floral meristem, producing a flower bud. A flower bud is the determined structure within which the flower primordia (sepals, petals stamens and carpels) are initiated.

Floral meristems have the same structural organization and general organogenic function as the SAMs, but produce different types of lateral organs and have different fates. First of all, in contrast to vegetative apical meristems, floral meristem is responsible for determination of growth, i.e. the limited growth of the flower of a particular size and shape, generating four types of the lateral organs - sepals, petals, stamens and carpels. Flower bud development depletes stem cell potential of the apical meristem so that further shoot development is not possible, however lateral buds behind the flower bud can develop into the new shoots and leaves. The transition from shoot meristem to floral meristem requires the activity of several floral meristem genes, which specify the floral organs and cause the termination of the production of stem cells.

Root apical meristem (RAM). The root apical meristem (RAM) has a subterminal position (unlike terminally located SAM) and it is covered by a root cap which protects the root apical meristem from mechanical damage and pathogens (Fig. 4B). During root growth, cells of the outer surface of the root cap are continuously sloughed off. But like SAM, RAM has also a layered structure. A central group of slowly dividing cells inside RAM is called the quiescent center (QC) 
(Fig. 4B, in blue). QC is formed early in embryogenesis from the hypophysis, the uppermost cell of the suspensor (see paragraph 2 "Embryogenesis"). Quiescent center is surrounded by the layer of initials (Fig. 4B, in green) the cells which are the derivatives of QC and which later give rise to different tissue types within the root. The experimental evidences suggest that both layers quiescent center and the zone of initials can be referred to as stem cells. Cells in the quiescent center (QC) in RAM are analogous to the cells of the organizing centre (OC) in SAM. Thus, both RAM and SAM contain groups of the stem cells with different level of their stem cell potential. During its growth the RAM contrary to the upper layers of the SAM produces cells in two directions: apical-basal and lateral.

Axillary meristems and indeterminate plant growth. Axillary meristems are derived from SAM and located within each module at the node just above the leaf attachment site. They have the same internal structure as the SAM, and can subsequently function as shoot apical meristems (SAMs) for each new shoot developed from this meristem. In case of activation under particular conditions or signals axillary meristem first develops into the axillary bud (also called lateral bud), which next may give rise to different structures such as new shoots (branches) or flowers.

The existence of axillary meristems provides plants with unlimited growth potential (Steeves and Sussex, 1989) and results on one hand in vast diversity in shoot architecture amongst plants and on the other hand in high variability of plant shapes and forms within one plant species. The appearance of shoot branches derived from axillary meristems is influenced by patterns of axillary shoot meristem initiation, lateral shoot bud development and lateral shoot branch outgrowth.

However, in most cases the main features of plant architecture are genetically predetermined. For example there are plant species with single, branched or multiple shoots and with single or multiple flowers per one shoot pattern, which indicate that bud formation and activity is unambiguously regulated axillary. Anyhow in some cases and under different conditions axillary bud activity can also be indeterminate and this leads to considerable variability in branching pattern, which can strongly influence the final shape and appearance of plant as each bud can in turn produce indeterminate (vegetative) or determinate (flower) structures.

Thus, regulation of the initiation and outgrowth of axillary meristems is an important mechanism for controlling overall plant form. Although in all cases axillary meristems arise in a close association with a leaf primordium, pattern of its development differs significantly among plant species.

For example in Heracleum axillary meristems arise from the surface of the leaf primordium. In Arabidopsis they are initiated either concurrently with the leaf as part of a common primordium or from the base of a developing leaf. Whereas in maize as it was shown by clonal analysis the axillary meristems are not associated with the leaf in whose axil they appear but are associated with the margins of the previously formed leaf (reviewed in Kerstetter and Hake, 1997).

In some axillary meristems the developmental pattern could be altered to produce a distinct structures such as a flowers, a tendrils, or a thorns meaning the transition to determinate growth of these meristems.

Adventitious meristems can potentially be initiated in all differentiated tissues of plant under specific conditions as the result from cell dedifferentiation followed by formation of meristematic 
locus, which capable to immediate form new organs. So-called adventitious shoots form normally on many different organs in a variety of plant species. Examples such as the root-bearing shoots of bindweed (Convolvulus arvensis), shoots initiated from the cambial tissue of tree stumps and vegetative meristems that arise on the hypocotyl of flax seedlings illustrate only a few of the spots at which adventitious shoots can form (Kerstetter and Hake, 1997). Under appropriate conditions cells in the pericycle of Arabidopsis roots that normally would form lateral root meristems can be coaxed into formation of shoot meristems instead. The development of organs or shoots upon a leaf or leaf homolog is known as epiphylly and there are naturally occurring examples of shoots forming on almost any part of the leaf. Among the more familiar examples are the piggyback plant (Tolmiea menziesii), which forms shoots at the junction between the petiole and the blade, and kalanchoe (Bryophyllum), in which plantlets form along the margin of the blade.

An epiphyllous shoot may represent the fusion or displacement of an otherwise normal axillary meristem or may represent a truly adventitious shoot occurring without any obvious relationship to either the primary or axillary shoot meristems. In the former normal axillary buds have been displaced onto the adaxial surface of the subtending leaf, the abaxial surface of the leaf above, and a variety of other stem and leaf positions. In these situations, meristem formation proceeds as in an axillary meristem but differential growth alters the position of the meristem relative to the other identifiable plant parts. In one example, the spiny shoots or aureoles on the cactus Coryphantha are initiated as vegetative meristems in the axils of the leaf but subsequently are carried up onto the summit of the leaf by differential growth on the adaxial side of the leaf base (Boke, 1952).

However in many examples of epiphylly it cannot be explained by the repositioning of an axillary meristem resulting from differential growth. In cases when shoots form in the axils of leaflets of a compound leaf, the leaf may have acquired so many characteristics of a shoot that the epiphyllous bud forms in a manner similar to a normal axillary bud.

Vegetative adventitious shoots often appear to be initiated by the remeristemization of less or more differentiated tissues of mature leaves. In kalanchoe, the epiphyllous shoots are derived from cells of the leaf margin, which precociously stop dividing and remain blocked in the G1 phase of the cell cycle (see Section 4 "Cell cycle"). In the mature leaf, these cells become reactivated to form an undifferentiated meristem that acquires zonation and forms a small shoot (Kerstetter and Hake, 1997).

Thus, it is obvious that under different conditions SAMs can be formed in a number of different locations in the plant, displaying different degrees of activity, and acquiring a variety of different fates during plant development. Regulation of SAMs' formation and activities is displayed by the phenomena of apical dominance, which means the suppression of formation and/or growth of additional SAM on lateral branches from axillary meristems by the activity of the dominant apical meristem of the main branch (stem, trunk). As a result the plant normally has only one clearly defined main branch. When the main branch stops its growth or damaged the lateral buds and other branches start grow much more rapidly.

For example, in trees the tip of the main trunk bears the dominant meristem. Therefore the tip of the trunk grows fast and is not shadowed by branches. If the dominant meristem is cut off one of the closest branch tips will assume dominance. The branch will start growing faster and the new growing branch can finally start function as the main trunk. When several branches' tips 
exhibit this dominant activity a bushy type of growth occurs. It was shown in many investigations that plant hormone auxin, which is produced in the apical meristem and then transported towards the roots via the cambium, plays a major role in this process. The possible molecular mechanisms underlying this phenomenon are discussed in Section 5.

Intercalary meristem. In angiosperms intercalary meristems occur only in monocotyledon plants at the base of stem nodes. Intercalary meristems implement rapid cell division and allow stem elongation during growth of monocots, as well as its regrowth in case of the damage. Sometimes the meristem at the base of the leaf blades are also referred as intercalary meristem but more often this one is referred as to separate type of meristem, basal meristem.

Basal meristem. In monocots during leaf formation the initial leaf bulge elongates until reaching a certain size. Then overall cell division stops and only cells in a small region near and parallel to the base of the leaf continue further divisions producing the typical longitudinal arrays of monocot leaves. This division zone is named basal meristem. Below this meristem a sheath that surrounds the stem is formed. The opposite side of this zone gives rise to the developing leaf blade. A leaf stalk is absent in monocotes. Leaf growth may continue without limitation as long as this meristem exists allowing damaged leaves to rapidly regrow. As a result of the basal meristem activity grasses can resume growth after mowing or grazing. Leaf formation in dicots is different and occurs without basal meristem formation The term basal meristem is sometimes also used for definition of a specific meristematic region in root where the lateral root positioning takes place (Ishikawa and Evans, 1995).

Secondary meristems. Vascular cambium produces secondary xylem and secondary phloem. The vascular cambium is a strand of elongated cells which divide to produce water-conducting tissue xylem on the inside, and sugar-conducting cells of phloem on the outside. Divisions of the vascular cambium lead only to an increase in girth but not in length. This process may last throughout the whole life of the plant. Activity of cambial cells results in the wood formation in certain plants. Such plants are called arborescent. In plants known as herbaceous there is no secondary growth.

The cork cambium is another type of secondary meristems. It is a layer of elongated cell located immediately beneath the epidermis of older stems and roots of woody plants. Cork cambium generates numerous parenchyma cells toward the surface, which then after death become the barky corky layers of the bark.

\subsection{Molecular mechanisms of meristem function}

There are several major groups of genes controlling and maintaining meristem function. Some of them maintains the stem cell activity, while the other genes lead to termination of the stem cell activity followed by switching to the organogenetic or to the flowering program under certain circumstances. During the transition to flowering the SAM switches from production of the vegetative buds to formation of the floral buds. 
It has been revealed that a number of specific genes are expressed in the particular loci of the SAM and the RAM to establish and maintain stem cell function of these meristems. These genes were discovered for the last less than two decades: 2 ASYMMETRIC LEAVES genes (AS1 and AS2), BELLRINGER (BLR), BLADE ON PETIOLE (BOP), BODENLOS, BREVIPEDICELLUS (BP), 3 CLAVATA genes (CLV1, CLV2 and CLV3 ), GIBBERELLIN-ACID INTENSITIVE (GAI),RGA, MONOPTEROS, SCARECROW (SCR), SHOOT MERISTEMLESS (STM), WUSCHEL (WUS), CUP-SHAPED COTYLEDON genes (CUC1, CUC2 and CUC3), LATERAL SUPPRESSOR (LAS), MONOCULUM1(MOC1), AGAMOUS (AG), LEAFY (LFY), SHORTROOT (SHR), ZWILLE/PINHEAD (Barton et al., 1993, Long et al., 1996, Endrizzi et al., 1996, Jackson et al., 1994, Lincoln et al., 1994, Laux et al., 1996, Mayer et al., 1998, Schoof et al., 2000,Clark et al., 1997, Stone et al., 1998, Jeong et al., 1999, Lenhard and Laux, 2003, Williams et al., 1997, Brand et al., 2000, Lynn et al., 1999).

The main pathway required for maintenance of stem cell fate in the shoot meristem is associated with the homeobox gene WUSCHEL (WUS) and three CLAVATA genes (CLV1, CLV2, and CLV3). (Laux et al., 1996, Schoof et al., 2000,Fletcher, 2002, Cock 2001; Mayer,1998, Clark et al., 1997, Stone et al., 1998, Jeong et al., 1999, Lenhard and Laux, 2003, Rojo et al., 2002) (Fig. 5A). WUS is expressed very early in embryogenesis and is limited to a few cells in the inner layers of the central zone. The function of WUS is maintenance of the stem cells proliferation, while the three $C L V$ genes negatively regulate $W U S$, limiting meristem size and leading to loss of meristem function and WUS expression. (Mayer, 1998) Thus, interactions between WUS and CLV genes establish negative-feedback loop to maintain the balanced population of stem cells in the apical meristem, in which two critical elements, WUS and $C L V 3$ are considered to be of the most importance for this regulation. While the presence of WUS gene prevents the differentiation of the stem cells, CLVI gene, expressing in the cells below the stem cells zone in the meristem, acts to promote cellular differentiation by repressing WUS activity outside of this central zone containing the stem cells (Williams et al., 1997, Brand et al., 2000). Also it was shown that 3 interacting CLAVATA genes are required to regulate the size of the stem cell reservoir in the SAM by controlling the rate of cell division (Fletcher, 2002).

There are some other meristem-specific genes important for distinguishing the proliferation zone of a meristem from the incipient primordia, namely the SHOOT MERISTEMLESS (STM) gene, which prevents stem cells from differentiation. This connected with repression of another gene, ASYMMETRIC LEAVES1 (AS1), whose expression is normally restricted to primordium founder cells.On the other hand, expression of AS1 represses other meristem regulators, for example, STM-related gene KNAT1 in the emerging primordia (Barton et al., 1993, Long et al., 1996, Endrizzi et al., 1996).

SHOOT APICAL MERISTEMLESS (STM) gene is expressed only in the cells committed to form embryonic SAM. Mutations in STM result in loss of meristem function. STM is also expressed in fluorescence meristem but disappears as floral bud is initiated. STM belongs to the $K N O X$ class genes, which are expressed in SAM and have the potential to establish stem cell fate in differentiated cells as it was shown that misexpression of KNOX genes leads to induction of ectopic meristems (Jackson et al., 1994, Lincoln et al., 1994, Wyrzykowska et al., 2002). More detailed molecular genetics investigations have revealed that WUS, STM, AS1 and KNAT1 genes 
encode the transcription factors.

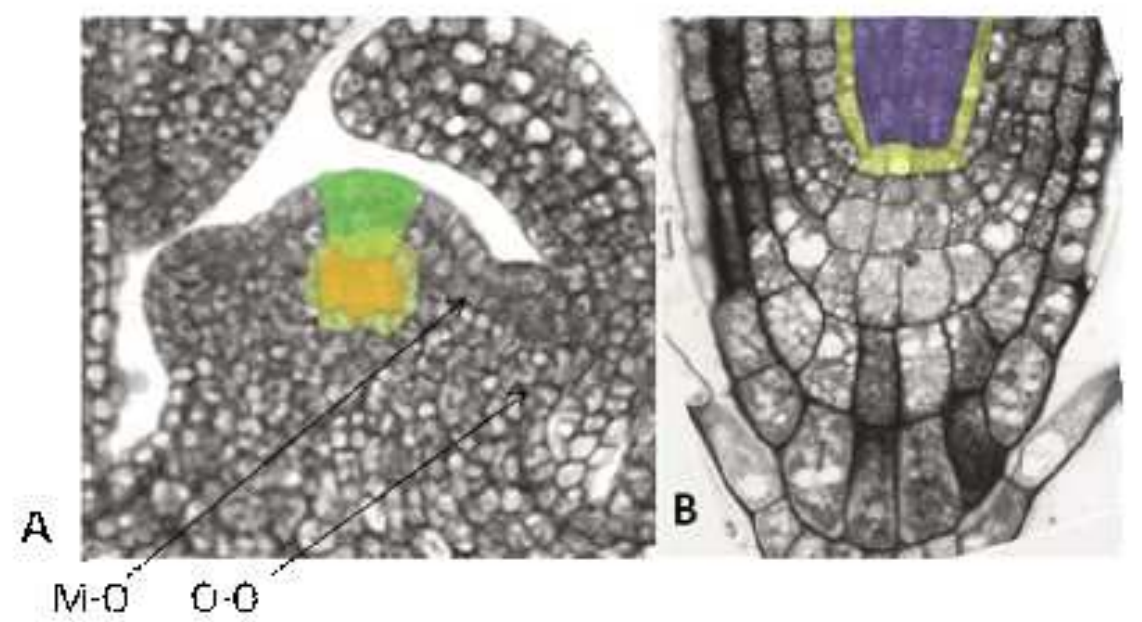

Figure 5: The gene expression patterns underlying meristem organization. A. In the SAM: CLV3 (green) is expressed in the central zone in the upper layers. CLVI (yellow) is expressed subterminally and overlaps with WUS expression (orange). WUS promotes CLV3 function in the cells above it. CLV3 signals through CLV1 to repress spreading of WUS. M-O - meristem-organ boundary, O-O - organ-organ boundary B. In the RAM: SCR (yellow) is expressed in the QC, adjacent ground tissue initials and the endodermis, $S H R$ (blue) is expressed in the stele and is trafficked into adjacent cell layer, the endodermis, where it directs cell fate. Published with the permission of the Current Opinion in Genes \& Development 2003, 13: 551-557.

One of the very important problem to be solved in the SAM development is the problem of boundaries formation in meristems since this is the initial mechanism by which lateral organ primordia are separated from the surrounding tissue (Souer et al., 1996, Laufs et al.,2004; Aida and Tasaka, 2006). Morphological and gene expression studies indicate the presence of a distinct set of cells defining the boundaries inside of the shoot apical meristem for example the boundary between meristem and organ primordia (M-O boundary) or boundary between two organ primordia (O-O boundary) (Aida, Tasaka, 2006) (Fig.5A).

Cells at the boundary usually display reduced growth activity that results in the separation of adjacent organs or tissues and thus morphological boundary also appears to be the border of cells of different identities. Such morphogenetic and patterning events and their spatial coordination are controlled by a number of boundary-specific regulatory genes. It has been revealed that many of the genes important for meristem initiation are also expressed inside meristem boundaries and their expression pattern is varying for different kinds of boundaries (Souer et al., 1996, Laufs et al., 2004). As a result these 'boundary cells' display different from the surrounding cells growth mode in which outward growth is usually suppressed forming a gap between adjacent primordia or between the primordium and the meristem.

The boundary may also act as a reference point for the generation of new meristems such 
as axillary meristems, which are generated at or close to the leaf axil, which is a derivative of the boundary between meristem and organ primordial (M-O boundary) in the primary meristem (Aida, Tasaka, 2006).

According to the recent work of Aida and Tasaka (2006) two representative expression patterns were found for the genes involved in organ - meristem boundary formation. Genes which has one type of expression pattern is expressed in the cells that give rise to the meristem. For example the Arabidopsis CUP-SHAPED COTYLEDON genes (CUC1, CUC2 and $C U C 3$ ) promote embryonic shoot meristem initiation and initially are expressed in cells between cotyledon primordia. The subset of these cells later forms the meristem but after the meristem becomes morphologically distinct these genes expression is down regulated in the meristem and becomes restricted to the boundary between the meristem and cotyledons (Aida et al., 1999; Vroemen et al., 2003). Similar expression dynamic was observed for LATERAL SUPPRESSOR (LAS) of Arabidopsis and its rice homolog MONOCULUM1 (MOC1) during postembryonic meristem formation. Both genes encode transcription factors required for axillary meristem formation and are expressed in the leaf axil, which contains the presumptive meristem (Greb et al., 2003). Expression of LAS is initiated in the meristem-organ boundary of a very young leaf primordium and continues until the axillary meristem initiation that occurs much later. Upon axillary meristem initiation its expression is down regulated in the meristem and is confined to the outer boundary, similar to that of the CUC genes.

Another pattern of gene expression does not coincide with the cells that form meristem, although these genes are required for primary meristem formation. The examples of these genes are petunia NAM gene, rice LAX gene, maize Branched Silkless1 and rice FRIZZY PANICLE. Aida and Tasaka,(2006) have concluded that these genes promote meristem initiation in a non-cellautonomous manner.

The transistion from the shoot meristem to the floral meristem requires activation of the floral meristem identity genes that specify the floral organs and cause the termination of the stem cells production. It was shown that the interplay between AGAMOUS (AG), LEAFY (LFY) and WUS genes is important for maintaining the floral identity and specificity.

The first gene AGAMOUS $(A G)$ is a homeotic gene required for the floral meristem maintenance and is necessary for proper development of the stamens and carpels. $A G$ prevents the conversion of the floral meristem back to the shoot meristem but it is not involved directly in the transition from shoot to floral meristem (Mizukami,1997). $A G$ is switched on by two other floral meristem genes $L F Y$ and WUS and is restricted to the centre of the floral meristem or the inner two whorls. $W U S$ activates $A G$ by binding to a consensus sequence in the $A G$ 's second intron and $L F Y$ binds to the adjacent recognition sites. An activated $A G$ represses expression of $W U S$ which leads to the termination of meristem (Lohmann, 2001).

In 1991 Coen, and Meyerowitz (1991) published their model of flower formation based on the expression of the selector homeotic genes. Later on it was shown those 3 genes encoding transcription factors: gene $A$ (Apetala2), gene $B$ (Apetala3) and gene $C$ (Agamous) are responsible for the orchestration of the formation of all flower organs, which are formed in four whorls: sepals, petals, carpels and stamens. Thus, it was demonstrated that sepal formation is encoded by gene $A$, petal by coexpression of gene $A$ and gene $B$, carpels by gene $C$, and stamens by coexpression of gene $A$ and gene $C$. The mutations in each of these genes lead to characteristic phenotype 


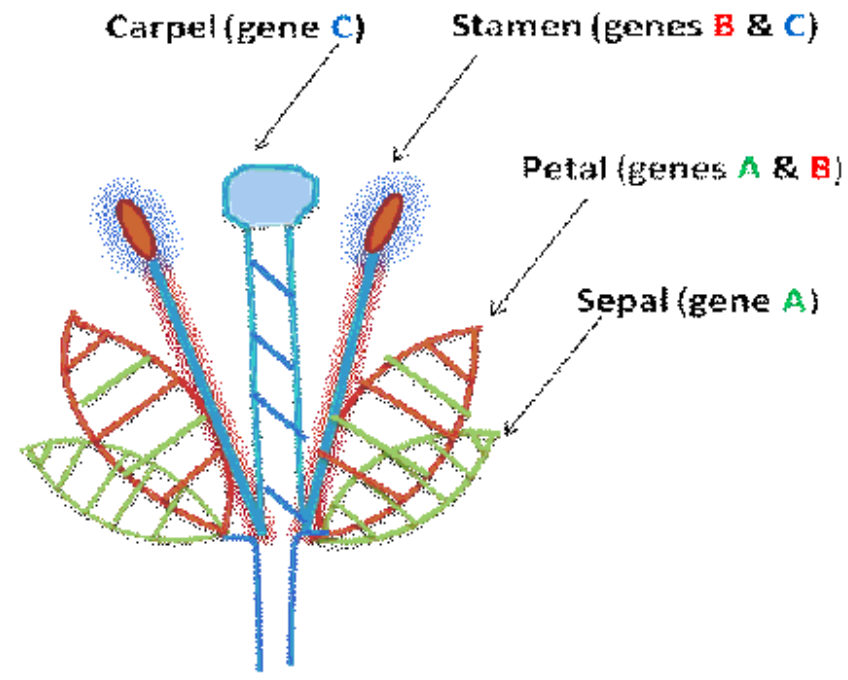

A Normalflower

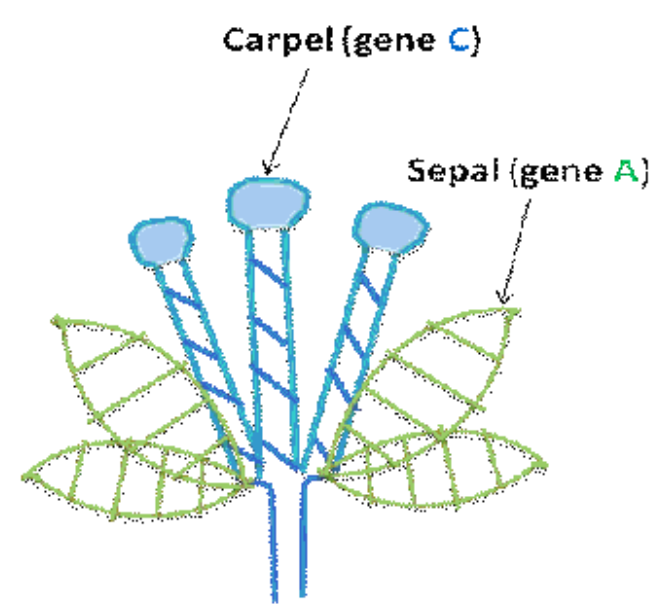

B Mutant Hower (not expressing gene B)

Figure 6: Regulation of flower organ formation by homeotic genes ABC. (See details in the text.)

with impaired pattern of flower organ formation. For example in the apetala 2 mutant the sepals are converted into carpels and the petals into stamens, while in apetala 3 mutant the petals are converted into sepals and stamens into carpels (Fig. 6) (Bowman et al., 1991).

It was concluded that the series of modified leaves corresponding to the particular organs forming a flower arise from the corresponding four whorls. The whorls are the equivalents of the segments in animal body pattern formation. Their development is controlled by homeotic genes the same way as series of segments during animal body formation.

The stem cell zones of root apical meristem (RAM) are also maintained by positional information based on the differential gene expression patterns. Thus, expression of gene MONOPTEROS is required for apical-basal patterning of the embryo and further on for initiation of the root meristem (Hardtke and Berleth, 1998). Another gene BODENLOS negatively regulates MONOPTEROS. Overexpression of BODENLOS results in loss of the root meristem (Hamann et al., 1999, 2002).

Transcription factor SCARECROW (SCR) is required for maintenance of the root meristem (Wysocka-Diller et al., 2000, Sabatini et al., 2003). SCR is expressed in the quiescent center (QC) of the root meristem in cortex initials and in differentiated endodermis (Fig. 5B in yellow). Activity of $S C R$ is required for QC cell identity and root growth. Loss of $S C R$ activity leads to disruption of stem cell identity in the root. SCR is also expressed in the L1 layer of the shoot meristem. SHORTROOT (SHR) gene is also required for patterning the root meristem. SHR is expressed in the stele (Fig. 5B in blue) (Helariutta et al., 2000, Nakajima et al., 2001). SHR activates $S C R$ in the cortex initials. Both $S C R$ and $S H R$ are required for QC function.

Phytohormone auxin plays an important role in the signaling underlying root formation (Saba- 
tini et al., 1999). MONOPTEROS encodes an auxin response factor, while BODENLOS encodes auxin response regulator. (see paragraph 5 for auxin signaling).

\subsection{The apical meristem as a source of cells}

There are three most important questions to be solved for understanding of the apical meristem structure and the prospective fate of its cells (Lyndon,1998):

- is it a single cell that always remains at the tip of the meristem and gives rise to all the rest or it is a group of several cells at the shoot apex, which works as the stem cells?

- do these initials always remain at the tip of the meristem or can they be displaced by adjacent cells which then become initials? If so, for how long (for how many plastochrons) can initial cells remain at the apex?

- are all apparent initial meristimatic cells equally qualified to be initials and can they become initials eventually?

The problem of the structure of the shoot apical meristem and the prospective fate of its cells are discussed in details in the works of Clawes (1961) and Lyndon(1998). Summarizing all data on this subject Lyndon came to the following conclusion: In theory there could be a single cell indistinguishable from the rest that always remains at the tip of the meristem and gives rise to all the rest as a true apical cell does. However, it also possible that there could be a group of two or more cells whose walls meet at the tip of the shoot apex.

Finally, by analyzing a lot of works devoted to the apical meristem study, Lyndon (1998) has concluded that presumably there are several cells at the top of the shoot from which all the rest are derived. All observations performed for examination of the growth at the shoot apical meristem tip, including direct microscopic observation on living apexes and placing marks on the apical surface and observing their displacement, showed that while most of the cells are displaced down the apical dome of the meristem there were apparently three cells at the tip of the meristem which persisted there during all period of observation and which could therefore be regarded as the initials.

If it is a group of several cells at the shoot apex, which work as the stem cells, than the point at which their cell walls meet would have to remain at the exact tip, because in the other case it would be displaced down the apex and some of these cells would lost their activity as initials. As long as the junction of these cells remains less than one cell breadth from the tip the cells can maintain their apical position and act as initials. In the experiments on Phaseolus seedlings the cell packets seen on the surface of apex appeared to be similar and suggested that all cells were dividing and could be potential initials. When the initial cells of the Lupinus shoot meristem were inactivated by pricking the top of the apex the wound was gradually displaced off the apical dome but the dome continued to function implying that other cells replaced the initial one(s). However, it is possible to assume that not exact centre of the dome has been destroyed or that the functional centre of the dome may be not the same one as the geometrical centre.

In order to answer the question for how many plastochrons can initial cells remain at the apex the following experiment was performed. The spots of carbon black were placed over the surface of the apical dome of Lupinus and it has been detected that most of them were displaced away from the top by growth of the apex. The amount of those marks which were not displaced considerably 
decreased with time and only $6.7 \%$ has not been moved in 42 days. If these marks correspond to those ones which had been placed on the actual initials then this means that they could stay for at least 13 plastochrons (Soma and Ball, 1963-citated by Lyndon, 1998).

The persistence of cells as apical initials can be followed over longer periods by the use of chimeras and by the technique of clonal analysis where it is possible to mark individual cells and follow their subsequent long-term fate (Poethig, et al., 1986; de Ruielle et al, 2006).

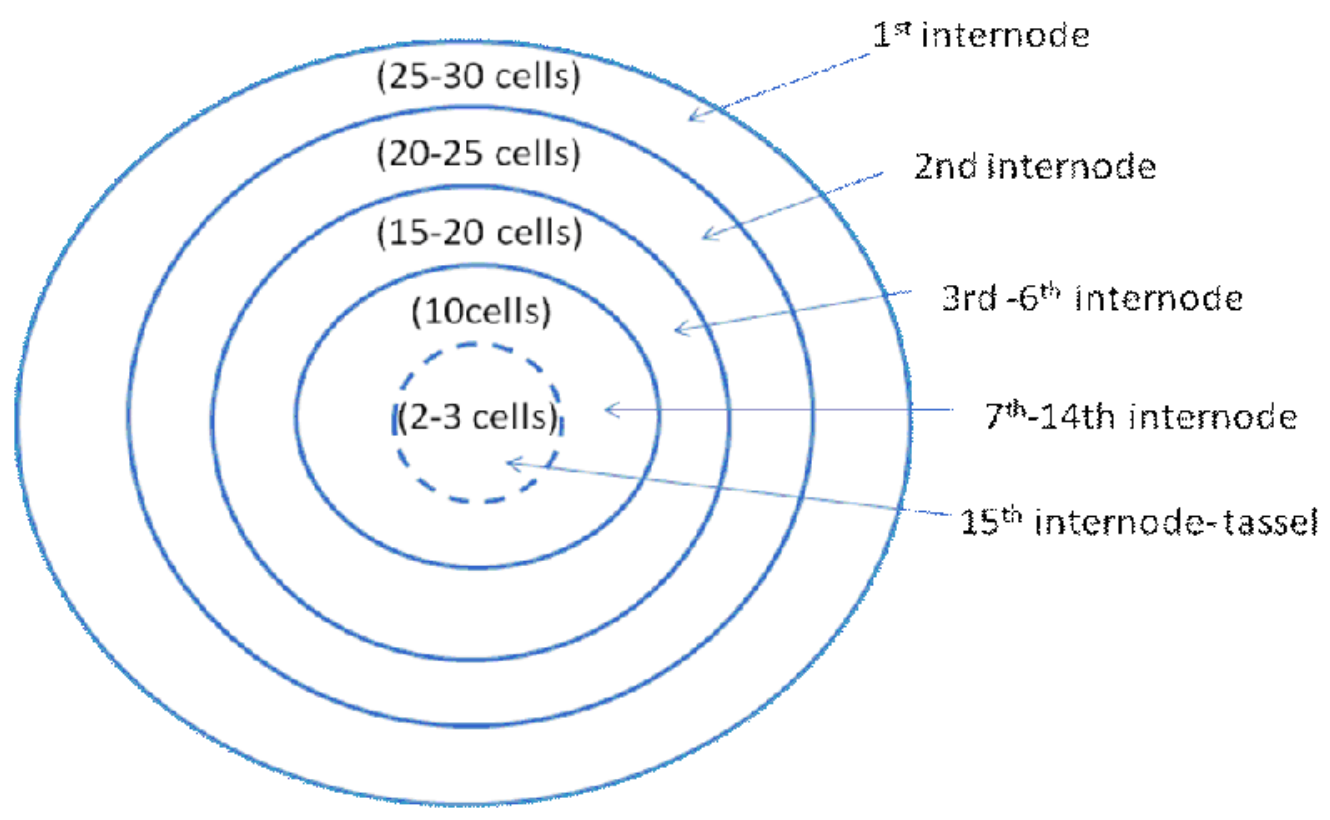

Figure 7: The fate maps diagram for the cells in the apical meristem of maize at the transition stage of embryogenesis. The epidermis of the apical dome (surface of the meristem) viewed from above is shown (from Poething et al, 1986).

Poething et al (1986) were able to construct fate maps for the cells in the apical meristem of maize. Before initiation of the shoot apical meristem there appeared to be two to three cells in the central-most ring at the top of the embryonic apex, and these are presumably the initials that can contribute to both the vegetative and reproductive shoot. During the transition stage of embryogenesis when the root and shoot meristems are beginning to become apparent, the shoot meristem consists of $72-88$ cells arranged in five concentric rings. As the shoot apex of maize grows from the proembryo to the transition stage in the seed increasing numbers of cell layers develop. The diagram presented in this work shows the shoot apex viewed from above as it is seen by microscopic observations of the embryo (Fig.7). The numbers in the rings indicate the number of cells in each layer at each developmental stage. The cell layers giving rise to the $1 \mathrm{st}-15$ th internodes and the tassel (the male inflorescence at the tip of the mature plant) can be identified. Two to three cells remaining at the top of the meristem give rise to only the last internode and the tassel. The whole of the shoot is derived from the two to three cells comprising the apex at the early and mid-proembryo stages (Poethig et al., 1986). In this example only the initials on the surface of 
the meristem have been considered but the structure of most meristems is more complicated than this including 3-dimensional structure of the initials (Luck and Luck 2000).

\subsection{Stem cells in plants and animals}

By definition stem cells are undifferentiated cells with the capability to differentiate into all or many tissues of adult organism. One of the main features of stem cells is the asymmetric cell division due to which they can both renew themselves and give rise to many mature specialized cell types (Fig. 8).

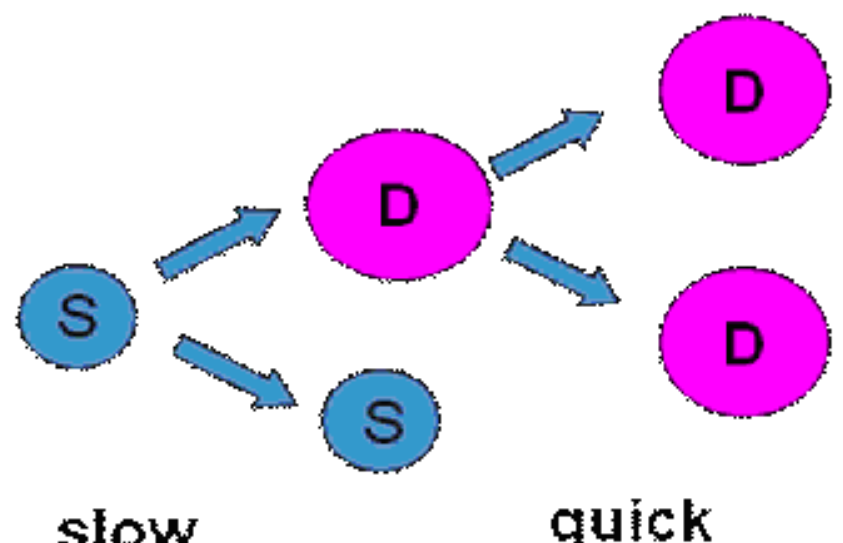

Figure 8: Asymmetric cell divisions of stem cells, producing 1 stem (S) and 1 differentiated (D) cell. Next divisions of differentiated (D) cells are symmetric, producing 2 equal daughter cells. The speed of stem cell divisions are much slower then divisions of differentiated cells.

The stem cells that are capable to produce all spectrum of cell types for the given organism are named totipotent cells, while those which are able to give rise to only several cell types are considered to be pluripotent cells. Although stem cells of different types are present in all organisms from both plant and animal kingdoms, the nature of stem cells, their production and localization, as well as their fate within the organism are very different in plants and animals.

In most animals only fertilized egg (zygote) and its descendant cells arising as result of a few consecutive divisions of zygote could be considered as the totipotent cells. These cells are known as embryonic stem cells. After early embryogenesis the potential to act as a stem cell in animal cells strongly decreases and developing cells undergo the transition from totipotency to pluripotency followed by the permanent differentiated state. During each next step towards the differentiated state cells gradually lose their ability to revert to the stem-cell fate and as the result almost all cells in adult animals are not totipotent. Most of the stem cells existing in an adult animal are pluripotent cells, such as those that generate blood cells. All animal stem cells are located in the special environment known as stem-cell niches, where they are maintained (Watt and Hogan, 2000, Whetton and Graham, 1999). 
Animal cells in differentiated state cannot undergo dedifferentiation and be converted back to the stem cell state, although some recent studies suggest that differentiated animal cells do retain plasticity and can be induced in specific experimental conditions to assume new fates (Liu and Rao, 2003, Tosh and Slack, 2002, Wilmut et al., 1997). But in vivo, except for some cases of regeneration in some animal phyla, the only result of the reprogramming of terminally differentiated animal cells would be tumorogenesis.

In contrast to animals totipotency in plants is not restricted to the zygote or the very early embryonic cells that arise from it. First of all in plants there are two permanently existing stem cells populations localized in the centers of shoot and root apical meristems. These populations are maintained as active stem cells during all lifespan of the plant. Normally cell divisions in the meristems are required to provide new cells for expansion and differentiation of tissues and for initiation of new organs. All plant postembryonic development occurs due to the activity of the meristems generated during plant embryogenesis. The root apical meristem produce the cells of the primary and lateral root system, while the shoot apical meristem is responsible for production of all others plant structures the stems, leaves and flowers determining therefore the basic structure of the plant body. The meristematic cells are functional analogous to the stem cells in animals, they are completely undifferentiated (or incompletely in some peripheral zones of meristem) and are capable to continued cellular division. Stem cells which are confined to the center zone of the shoot and root meristems divide slowly and give rise to two types of daughter cell. The cells that stay in the centre remain stem cells, whereas daughter cells that are displaced to the periphery of the meristem enter a developmental pathway that leads to differentiation into root- or shoot-specific cells or specific organs such as leaves either to initiation of secondary meristems.

Many differentiating plant cells are able to become stem cells again. As most of plant cells continue to be totipotent throughout the plant's life and under appropriate conditions in vivo and in vitro the whole plant or different plant organs (shoots, roots, flowers) can be propagated from the single cells taken from different parts of the plant. To gain the totipotency the differentiated plant cell has to undergo a process known as dedifferentiation. Due to the property of totipotency intrinsic to the plant cells a lot of plant species along with sexual reproduction also exploit vegetative reproduction when the whole plant grows out of the specialized vegetative structures formed at some point from the differentiated somatic cell(s). Ability of many plant species to somatic embryogenesis in vitro and even in vivo is the result of plant cell totypotency. It was shown that mutations increasing the size of the embryonic shoot meristem also increase the frequency of somatic embryos induction, which could be interpreted as the correlation between stem-cell function and somatic embryogenesis (Mordhorst et al., 1998). Formation of so-called adventitious meristems almost on all plant organs from differentiated cells in a variety of plant species takes place due to totipotency as well.

Most of differentiated cells, however, do not normally form meristems. Detailed mechanisms and conditions that are required for the adventitious meristems formation remain to be discovered (Weigel and Jurgens, 2002). Although a lot of data about genetic and molecular basis of the primary meristems organization have currently been obtained much less details are known about the molecular regulation of dedifferentiated plant cells. 


\section{Cell proliferation (cell cycle progression)}

\subsection{Phases of Cell cycle}

The cell cycle progression is the serial process of cell division and replication resulting in the appearance of new daughter cells containing DNA identical to the mother cell. Further each of the new daughter cells can also undergo cell cycle events forming a cascade of repeating cycles. The cell cycle consists of four phases: G1 phase, S phase, G2 phase and M phase (Fig.9).

Although the various stages of cell cycle are not always morphologically distinguishable, each phase of the cell cycle has a distinct set of specialized molecular processes that prepare the cell for new cell division. Activation of each phase is dependent on the proper progression and completion of the previous one. Cells that have stopped divisions and entered a state of quiescence are considered to be in G0 phase.

G1 (gap1) phase starts after the end of the mitotic (M) phase with the appearance of the new daughter cells from the previous mother cell. G1 is finished with the beginning of DNA synthesis (S phase). During G1 phase synthesis of the various types of transcription factors and other important regulators required for DNA replication in the following $S$ phase takes place. Duration of G1 phase is highly variable between species and during different periods of developmental process of the given organism and is strongly dependent on some internal and external factors.

$\mathrm{S}$ phase corresponds to DNA synthesis and ends when all of the chromosomes have been replicated, i.e., the amount of DNA in the cell at this phase is doubled. Rates of RNA transcription and protein synthesis are very low during this phase with an exception for histones proteins production, most of which occurs during the $S$ phase (Nelson et al., 2002). The duration of S phase is relatively constant among cells of the same species.

G2 phase is the second gap phase, which is necessary for the preparation of cell to enter mitosis. All biosynthetic processes occurring at this phase are involved in the production of different components facilitating cytokinesis (the process of daughter cells separation), such as septins, microtubules, etc. Inhibition of protein synthesis during G2 phase prevents the cell to enter mitosis.

$\mathrm{M}$ phase corresponds to mitosis the process under which two identical daughter cells are produced from the original parent cell. Mitosis involves both nuclear division (karyokinesis) and cytoplasm division (cytokinesis). In plants cytokinesis is accompanied by the formation of new cell wall.

The karyokinesis is a complex process consisting of the five phases: prophase, prometaphase, metaphase, anaphase and telophase. In the course of kariokinesis each chromosome consisting of two sister chromatids reduplicates by moving the sister chromatids along the division spindle towards the opposite poles of the cell. As a result of the kariokinesis partition of a cell's nucleus occurs. Finally, cell undergoes cytokinesis dividing into two identical daughter cells. Normally cytokinesis occurs as a necessary part of mitosis, but there are many cases where mitosis and cytokinesis occur separately forming single cells with multiple nuclei. For example, in some cases in animals cytokinesis and mitosis occur independently during early stages of embryogenesis (see embryogenesis of Peonia described earlier in this paper ?2).

Nonproliferative cells in multicellular eukaryotes generally enter the quiescent G0 state from 
G1 and may remain indefinitely quiescent for a long period of time. This is very common for the cells that are fully differentiated, e.g. neuron cells. Conception of the G0 phase so as the term "post-mitotic" cell, can be used to refer to both quiescent and senescent cells. Cellular senescence is a state that occurs in response to DNA damage or degradation that would make a cell's progeny nonviable; it is often a biochemical alternative to the self-destruction of unnecessary cells by apoptosis. Some cell types in mature organisms enter the G0 phase semi-permanently and can only be induced to begin divisions again under very specific circumstances.

For proper regulation of the of the cell cycle progression, e.g. for verification of necessary phase processes, repairing of DNA damages and preventing cell cycle progression into the next phase until all the requirements have been met several checkpoints exist in the cell cycle to ensure that damaged or incomplete DNA would not pass into daughter cells. Two main checkpoints are: the G1/S checkpoint and the G2/M checkpoint. G1/S transition is a rate-limiting step in the cell cycle and is also known as restriction point. Antiapoptotic protein p53 plays an important role in triggering the control mechanisms at both G1/S and G2/M checkpoints (see review Alberts et al., 2008)

\subsection{Molecular mechanisms of cell cycle regulation}

There are two classes of main regulatory molecules involved in cell cycle regulation: cyclins and cyclin-dependent kinases (CDKs) (Nigg , 1995). Most of the genes encoding cyclins and CDKs are conserved among all eukaryotes but in more complex organisms cell cycle is controlled by additional specific components.

The main function of CDKs is the phosphorylation of target proteins playing important roles in different steps of cell cycle. The phosphorylation leads to the activation or inactivation of the corresponding proteins and thus controlling their activity during cell cycle. To be able to perform the act of phosphorylation each cyclin-dependent kinase should be activated by a corresponding cyclin. Different cyclin-CDK combinations regulate particular downstream target proteins. Interestingly while CDKs are constitutively expressed in cells cyclins of all types are synthesized at specific stages of the cell cycle in response to various molecular signals.

Upon receiving an extracellular signal corresponding to mitosis cyclin-CDK complexes of G1 phase (involving cyclinD or cyclinE and cdc4 or cdc6) become active and in turn activate the expression of transcription factors involved in the expression of $\mathrm{S}$ cyclins and enzymes required for DNA replication. These complexes are also involved in the degradation of S phase inhibitors by targeting them for ubiquitination, which means the signal for proteolytic degradation of this target by the proteasome system.

Active $\mathrm{S}$ cyclin-CDK complexes (involving cyclinA) phosphorylate proteins that make up the pre-replication complexes assembled during G1 phase on DNA replication origins. The phosphorylation activates each already-assembled pre-replication complex and prevents formation of new complexes. This ensures that every portion of the cell genome will be replicated once only.

Mitotic cyclin-CDK complexes (involving cyclinB and cdc2), which are synthesized but inactivated during $\mathrm{S}$ and $\mathrm{G} 2$ phases promote the initiation of mitosis by stimulating downstream proteins involved in the chromosome condensation and mitotic spindle assembly. A critical complex ac- 
tivated during this process is ubiquitin ligase known as the anaphase-promoting complex (APC), which promotes degradation of structural proteins associated with the chromosomal kinetochore. APC also targets the mitotic cyclins for degradation ensuring that telophase and cytokinesis can proceed.

The most important event in the cell cycle progression is the G1/S transition, which depends on passing through the G1/S restriction point. The key molecular regulator of the restriction point are retinoblastoma protein (RB) and transcription factor E2F (Elledge, 1996, Herwig and Strauss, 1997).

During early G1 phase in response to the extracellular signals (for example, to growth factors) cyclin $\mathrm{D}$ is produced and next binds to CDK4 forming the active cyclin D-CDK4 complex. This complex then phosphorylates the retinoblastoma protein (RB). RB protein in its nonphosphorylated form binds to the transcription factor E2F (usually presents in a form of E2F/DP1 complex) blocking therefore the transcription of corresponding genes important for transition to $S$ phase (Fig.9). Being hyperphosphorylated RB dissociates from the E2F/DP1/RB complex, thus re-activating E2F. As activation of E2F results in the transcription of various genes involved in the regulation of the next phases of cell cycle, e.g. cyclin E, cyclin A, DNA polymerase, thymidine kinase, etc. passing through this restriction point normally means that the cell cycle will be successfully fulfilled. Cyclin E binds to CDK2 forming the cyclin E-CDK2 complex important for progressing to $\mathrm{S}$ phase. Next cyclin A along of CDK2 forms the cyclin A-CDK2 complex, which initiates the G2/M transition. Cyclin B-CDK1 complex activation causes breakdown of nuclear envelope and initiation of prophase. Subsequently its deactivation causes the cell to exit mitosis.

Beside of the cyclin-dependent kinases, cyclins, RB and E2F proteins there is another group of molecules important for proper regulation of the cell cycle progression. This group includes two families of genes the Cip/Kip family and the INK4a/ARF family (Inhibitor of Kinase 4/Alternative Reading Frame), which work as an inhibitors of the cell cycle progression. Due to their role in prevention of tumor formation these genes are also known as tumor suppressors. The Cip/Kip family includes the genes p21, p27 and p57. They arrest cell cycle in G1 phase by binding to and thus inactivating cyclin-CDK complexes. One of the important signaling pathway for cell cycle arrest is a response to DNA damage causing p21 activation mediated by p53 protein. The INK4a/ARF family includes p16/INK4a, which arrests the cell cycle also in G1 phase by binding to CDK4 and p14/arf that prevents p53 protein degradation (Hanahan et al.,2000, Sherr et al.,1996, Evan et al., 2001).

All molecular mechanisms of cell cycle regulation presented above are very similar in plants and animals (Howell S.H. 2000, Alberts et al., 2008, Grafi, 2004). However, as the process of cell dedifferentiation starts with the re-entry of the given cell into the cell cycle, it appears to be important to elucidate the factor(s) of cell cycle regulation which might explain high level of plant cells plasticity contrary to terminal differentiated status of animal cells. One possible explanation could be that in plants cell cycle progression is regulated by plant hormones. It was proofed that cell cycle is regulated by auxin in cyclinD- E2F-RB pathway (Traas and Bohn-Courseau, 2005; Magyar et al., 2005; Boucheron et al., 2002; Himanen et al., 2002) ,by cytokinin in cdc2-cyclinB and in cyclinD-E2F-RB pathways (Boucheron et al., 2002; Soni et al., 1995). It was reported that a possible mechanism of auxin-mediated cell cycle activation could be realized by the splitting of the 


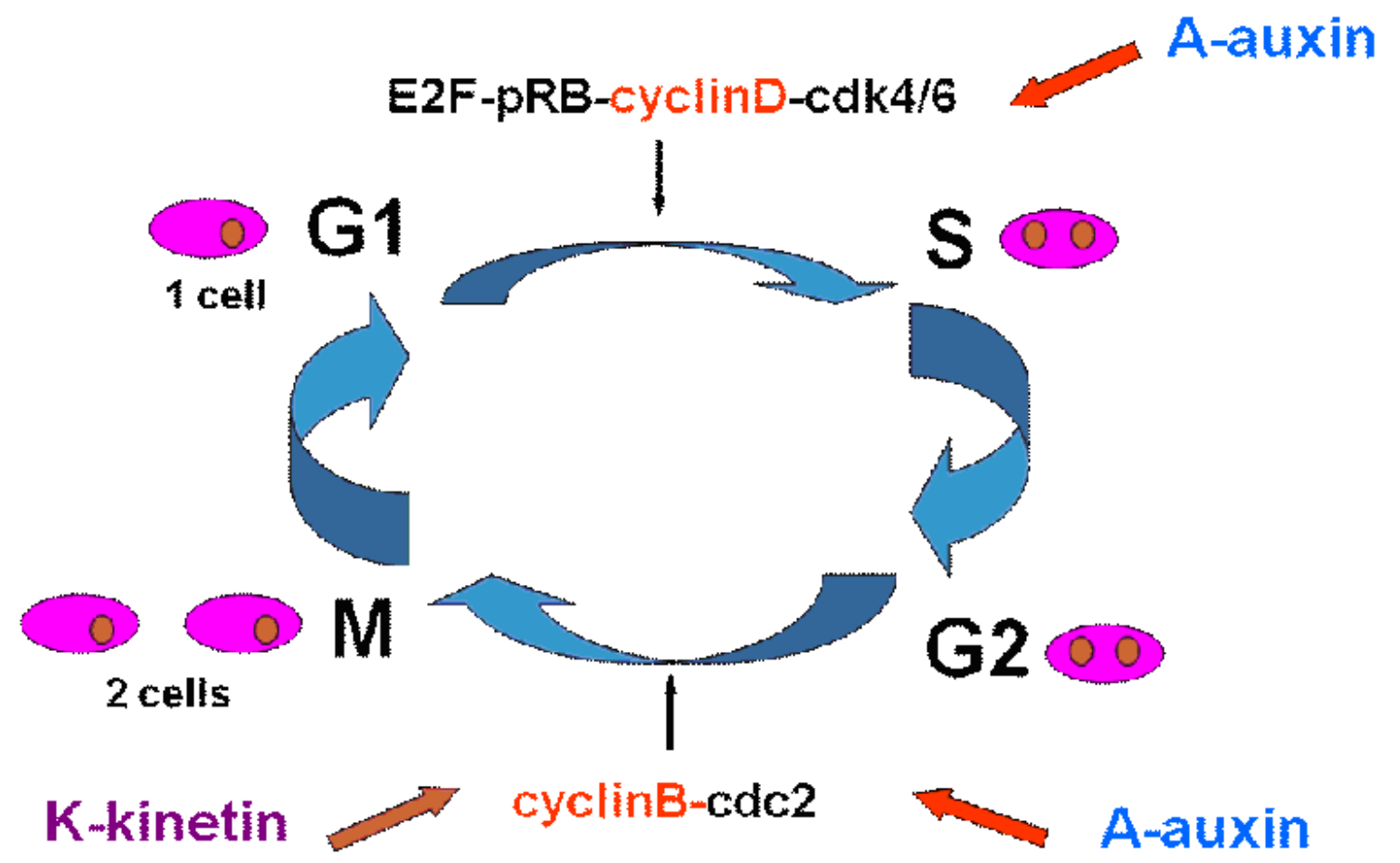

Figure 9: Cell Cycle Progression and its control by plant hormons. (See details in the text.)

E2F-RB complex by auxin, which positively regulates the passage through the G1-to-S restriction point (Traas and Bohn-Courseau, 2005; Magyar et al., 2005). Cytokinin influences the cyclinBcdc2 complex and positively regulates G2-M transition (Boucheron et al., 2002; Soni et al., 1995) (Fig.9).

\section{Current data on exceptional role of auxin in pattern forma- tion and development in plants}

\subsection{Role of auxin in plant pattern formation}

The exceptional role of plant hormone auxin in formation of plant organs was shown and discussed in many recent reports(Okada et al., 1991; Heisler et al., 2005; Treml et al., 2005; Reinhardt,2005; Smith et al., 2006; Jonsson et al., 2006; Fleming, 2005; Thingnaes et al., 2003; Sitbon et al., 2000; Delisle, 1937; Went, 1944; Benkova et al.,2003; Casimiro et al., 2001; Reinhardt et al., 2000, 2003; Blilou et al., 2005; Vernoux et al., 2000; Galweiler et al., 1998; Aida et al., 2002; Stieger et al., 2002).

It has now been well established that auxin is produced in the growing (proliferating) parts of the plant and is transported from them via phloem to other plant tissues (reviewed in Clowes, 1961; 
Lyndon, 1998). Auxin is one of the major player in plant growth and development, such as apical dominance, tropisms, vascular patterning, and axis formation. A lot of recent studies point out that hormone auxin is the main factor for the positioning and developing of new buds as the highest auxin level corresponds to the places of initiation of bud formation. Auxin has also been shown to induce leaf and flower formation at the shoot apical meristem (SAM) determining thereby the organ position and phyllotaxis (Reinhardt et al., 2000, Reinhardt et al., 2003). Transport of auxin is an important signal for initiation and maintenance of the root meristem (Sabatini et al., 1999). Auxin plays important role in longitudinal positioning of the quiescent centre (QC) inside it.

Last years much work has been done to elucidate the details of auxin regulatory activity (Billou et al., 2005, Swarup et al., 2001, Galweiler et al., 1998 , Schindelman et al., 2001, Friml et al., 2002, Geldner et al., 2004, Friml et al., 2003, Jurgens and Glendner, 2002 , Ljung et al., 2005, Friml, 2003) .

However, there is a lot of uncertainties and contradictions about the role and the mechanisms of auxin signaling. For example, most biological observations show that auxin concentration is greater in the proliferating parts of the plant tissue but there are also some reports showing that an excess of auxin can stop proliferation (Lyndon, 1998, Meicenheimer, 1981).

Thus, the idea that the points of new bud formation correlate with higher auxin level (Zhu and Davies, 1997; Reinhardt et al., 2000, 2003; Blilou et al., 2005; Vernoux et al., 2000; Galweiler et al., 1998; Aida et al., 2002; Stieger et al., 2002; Himanen et al., 2002) co-exists with the observations that auxin concentration in these points is lower than in the surrounding cells (Clowes, 1961; Lyndon, 1998; Heisler et al., 2005) and finally with the statement that auxin except for the very low concentrations inhibits bud formation and bud development (Thimann et al., 1933,Skoog, 1954, Stirnberg et al, 1999, Reinhardt,2003). The data that auxin concentration needed for bud formation is less than that needed for cell proliferation (Lyndon, 1998) are also contradictive.

Some of the recent studies show that bud development, after its initiation, is related to depletion of auxin from the growing bud, which starts to work like a sink of auxin transporting it to the lower layers or to the phloem (Heisler et al., 2005; Reinhardt et al., 2003; Stieger et al., 2002). However, it is not yet clear whether it is a flow of auxin that is essential for bud development or decrease of its concentration.

The fact that auxin works as a trigger of bud formation seems to be the same for leaf and for flower bud development. In most publications no difference between auxin influence on leave or flower bud has been reported, except of Zhu and Davies (1997) where it is affirmed that auxin content is lower in the flower bud than in the leave bud. It was shown that some of the genes highly expressed in flower and in vegetative buds are regulated by auxin, but this is true for both types of buds (Okada et al., 1991; Heisler et al., 2005; Reinhardt, 2005; Smith et al., 2006; Jonsson et al., 2006; Fleming, 2005;Stirnberg et al., 1999; Rajeevan and Lang, 1993). However, the role of auxin in transition to flowering was supported by showing the role of auxin transport in influencing the primordial cell (Heisler et al., 2005).

The attempts to understand the key role of auxin in plant organ formation has elucidated the importance of auxin transport towards the certain directions and therefore its nonuniform distribution. For example it was shown that inhibition of normal auxin transport in roots impairs the positioning of the QC in root apical meristem and results in expression of QC-markers in cells 
above of the QC( Sabatini et al.,1999, Jiang et al.,2003).

Many recent discoveries have shown that the important mechanism underlying the specified auxin distribution is the polar transport of auxin (Mravec et al.,2008, Treml et al., 2005; Reinhardt, 2005;Smith et al., 2006; Jonsson et al., 2006; Fleming, 2005; Reinhardt et al., 2000, 2003;Blilou et al., 2005; Vernoux et al., 2000; Galweiler et al., 1998; Aida et al., 2002). Auxin as a part of phloemmediated up- and downstream transport has its own active (polar) transport routes implemented by the specific proteins working as an efflux and influx auxin carriers in the plasma membrane represented by PIN and AUX protein families correspondingly (Bennett et al., 1996, Galweiler et al., 1998). According to T. Steinmann et al. (1999) the auxin distribution is based on the expression pattern and subcellular localization of the AUXIN RESISTANT1 (AUX1) (Bennett et al., 1996) and PIN-FORMED1 (PIN1) (Galweiler et al., 1998) proteins, and on their directed traffic from endosome to the specific subdomains of the cell membrane. The PIN recycling machinery in turn depends on the vesicle transport of PIN proteins for which the ARF-GEF protein GNOM is required (Steinmann et al., 1999, Geldner et al., 2001). Further analyses revealed that five PIN proteins in Arabidopsis bear different functions equally important for polar auxin transport and following organ formation. These researches also showed the maximal association of these proteins with auxin in distal domains of organ primordia ( Billou et al., 2005, Friml et al., 2003, Benkova et al., 2003, Dhonukshe et al., 2008 ).

However, in a number of most recent investigations auxin efflux carrier PIN1 protein is considered to be the key player in the auxin-mdiated regulation of bud initiation and plant organ formation (Heisler et al., 2005; Treml et al., 2005; Reinhardt, 2005; Smith et al., 2006; Jonsson et al., 2006; Fleming, 2005; Reinhardt et al., 2000, 2003; Blilou et al., 2005; Vernoux et al., 2000; Galweiler et al., 1998; Aida et al., 2002; Stieger et al., 2002). On the other hand, it was shown that regulation of the PIN genes is itself under the auxin control via PLETHORA gene feedback loop (Blilou et al., 2005). Therefore, finally it was concluded that auxin induce auxin efflux which can be considered (and modeled) with or without of the intermediate PIN protein(s) involvement.

The detailed analysis of auxin action in the process of bud formation showed that auxin itself cannot initiate cell proliferation. It can happen only in the presence of cytokinin, another plant hormone (actually this is a group of hormones) the main role of which is the regulation of cell proliferation. On the other hand, initiation of cell proliferation alone does not lead to leaf initiation (Wyrzykowska et al., 2002). Therefore, it can be an interplay of these two hormones that causes formation of a new bud. Experiments on plant cell culture show that the main factor for the regulation of cell growth, cell differentiation and for the initiation of specific processes of organogenesis is the auxin/cytokinin ratio. Namely, it is shown that the increase of the auxin/cytokinin ratio in callus causes formation of roots while the decrease of this ratio results in shoot formation (Skoog and Miller, 1957; Yamaguchi et al., 2003).

It is also known that bud formation can be initiated by auxin in the place of a sufficient level of metabolic activity (Pien et al., 2001; Reinhardt et al., 1998; Cosgrove, 2000).This correlates with the observations that the sugar content (mostly sucrose) is elevated in the cells undergoing organogenesis (Borisjuk et al., 2003; Rosche et al., 2002; Leon and Sheen, 2003; Lorenz et al., 2003). It can be an independent factor, but there is a number of works showing that auxin causes the afflux of sugars (Zhu and Davies, 1997), phosphates (Lopez-Bucio et al., 2002) and nitrates 
(Himanen et al., 2002) to the place with its high content.

One of the crucial process in which auxin has been involved is the phenomena of apical domination - suppression of the lateral branches growth by the apical meristem of the main branch. In the cases when the main branch of the plant stops growing or damaged, the release from this supression occurs and the lateral buds start growing. As it is shown in many investigations, auxin plays a major role in this process (Lyndon,1998).

The apical meristem is the main place where auxin is synthesized and from where it is then transported to the other plant tissues. The release from apical domination (e.g., after cutting off the apex of the main branch) is correlated with a decrease of the auxin level in lower parts of the plant. This can initiate growth of lateral branches. Application of the external auxin to the region of the cut apex can stop growth of the new lateral branches, which obviously indicates the involvement of auxin signaling in the process of bud formation.

Anyhow, the current paradigm that auxin produced in the apical meristem of the main branch prevents growth of new branches from lateral buds seems contradictory. Because if the concentration of auxin in the lateral bud is too high, such that it prevents growth of the new branches, then its concentration in the apical meristem is even higher and should prevent growth of the main branch. Thus, we come to the conclusion that auxin produced in the apical meristem cannot prevent growth of new branches unless there are some other factors that should be taken into account.

One way to overcome this contradiction is to assume that it is not solely auxin but a complex of metabolic factors influencing bud growth and being involved in the phenomena of apical domination. First of all there are some observations confirming that the mechanism of apical domination is rather related to the interaction of the mechanism regulating cell cycle progression, which in turn depends on auxin concentration and also on nutrients supply (Bessonov et al., 2008 ).

One example confirming this point of view is the process of the transition to flowering (evocation). It was shown that evocation frequently results in the development of axillary buds indicating a release from apical domination. But auxin production or its level does not seem to be essentially changed during the evocation. The most critically important characteristics of the apex during the evocation is an increased growth rate and a shortened cell cycle (Clowes, 1961). An important role of the flux of nutrients on the interconnection of plant organs is confirmed by the fact that removal of lateral branches stimulates growth of fruits.

Another observation is that while the application of the external auxin to the apical meristem can stop growth of lateral branches the application of external cytokinin to the dormant buds can initiate growth of new branches though the auxin level in the buds is not changed.

\subsection{Different biological models of auxin-dependent phillotaxis and organ formation}

There are several different models of auxin-dependent phillotaxis and organ formation emphasizing genetic, biosynthetic, or transport aspect of the problem. However, all these models consider as a main factors of auxin-dependent plant pattern formation the proteins involved in auxin transport, mostly PIN proteins. 


\subsection{1. "Sink model” (Reinhardt et al., 2003)}

In this model it is shown how proteins involved in auxin transport regulate phyllotaxis in Arabidopsis. The main idea of the model is that auxin is transported upwards into the meristem through the epidermis and the outermost meristem cell layer. Existing leaf primordia act as sinks redistributing auxin and creating its heterogeneous distribution in the meristem. Auxin accumulation occurs only at certain minimal distances from existing primordia defining the position of future primordia.

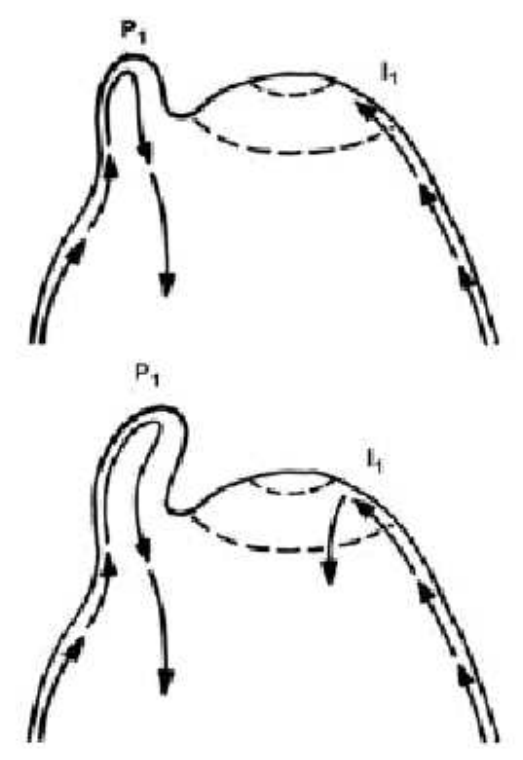

Figure 10: Model for the role of polar auxin transport in phyllotaxis. Schematic representation of an apex in longitudinal section through P1 and I1 at an early (top) and a later stage (bottom) of incipient primordium formation. Polar auxin flux is indicated with arrows. Top, acropetal auxin flux is diverted by P1 preventing auxin accumulation on the left flank of the meristem, while auxin can reach the right flank (I1). Bottom, accumulation of auxin at I1 promotes primordium formation, and establishment of a new auxin sink (from D. Reinhardt et al., Nature, 426 (2003), November, 255-260).

According to the model (Fig. 10) auxin is acropetally transported towards the meristem. In the meristem auxin becomes absorbed by the primordia, which function as sinks. As a result auxin is depleted from the surroundings of the primordia and reaches the organogenetic peripheral zone only at a certain minimal distance from P1 and P2 (corresponding to the I1 position). Auxin accumulation at I1 induces a new primordium, which in the course of the plastochron will grow out and itself become a sink for auxin. This mechanism represents a combination of positive feedback (auxin accumulation) and lateral inhibition (withdrawal of auxin from adjacent tissues) that could conceptually be compared with the short-range activator and the long-range inhibitor in reaction-diffusion mechanisms.

The described system means the dynamic regulation of PIN1 during the course of the plas- 
tochron. Indeed, cellular redistribution of the PIN1 protein can be extremely rapid and could easily allow for the $137^{\circ}$ shift in orientation required during each plastochron. The author suggested that in the shoot apical meristem could be active a similar mechanism that was shown for the root (Steinmann et al.,1999; Geldner et al.,2003) where the subcellular localization of PIN1 is dynamically regulated by GNOM, which is a component of the vesicular cycling mechanism. Except of PIN1 there are several other genes which can also contribute to phyllotactic patterning.

For example genes PINHEAD/ZWILLE are expressed in a phyllotactic pattern below the meristem and thus could be important for final patterning (Lynn et al., 1999). Essential effectors involved in translation of auxin signaling into actual growth patterns are such factors as CUP-SHAPED COTYLEDON1 and 2 (CUC1 and CUC2) for organ separation(Aida et al., 2002), and expansion for organ outgrowth (Fleming et al., 1997, Reinhardt et al., 1998).

The main advantage of this model is that it accounts for the Reiterative and the stability of organ positioning. For understanding how the divergence angles are determined, it was proposed that if only $\mathrm{P} 1$ is effective as a sink then a result would be a distichous phyllotaxis (divergence angle 180?). Higher-order phyllotactic systems will result from the contribution of increasing numbers of primordia. Important parameters influencing relative sink strength are likely to be the size of the central zone relative to the organogenetic zone (plastochron ratio) and the growth rate of the apex along the apical-basal axis. In addition the timing of the transition of primordia from auxin sinks to auxin sources will influence phyllotaxis.

\subsection{2. “Family of PIN proteins in Embryogenesis" model (Friml et al., 2003)}

This model describes a dynamic distribution of auxin and its response during early embryogenesis and suggests routes of auxin transport, providing the first coherent conceptual framework of the apical-basal axis establishment. The family of PIN proteins as a auxin afflux carriers plays the most important role in this model.

According to this model immediately after division of the zygote auxin accumulates in the smaller apical cell. Auxin response is activated and the cell is specified as founder of the proembryo (Fig. 11a). Auxin is actively provided here from the adjacent basal cell by PIN7-dependent transport as both chemical efflux inhibition and pin 7 mutations cause failure of the establishment of the apical-basal auxin gradient and lead to auxin accumulation in the basal cell. Moreover, PIN7 is polarly localized to the apical plasma membrane of the basal cell where it is perfectly positioned to provide auxin to the adjacent apical cell. This apical-basal auxin distribution mediates correct specification of the apical cell, because this specification is compromised in pin 7 mutant and even more strongly in quadruple pin mutants as demonstrated by aberrations in both cell behaviour and marker expression. Thus, an actively maintained PIN-dependent auxin gradient is required for the specification of the apical cell, which later becomes the founder of the proembryo and all apical structures of the plant.

At the globular stage (Fig.11b) bioactive auxin production probably starts in the apical region of embryo. In support of this hypothesis indicates the fact that auxin response is activated ectopically in the apical region as response to chemical inhibition of auxin transport or in gnom mutants. At the same stage PIN1 basal localization is established in the provascular cells suggesting downward 

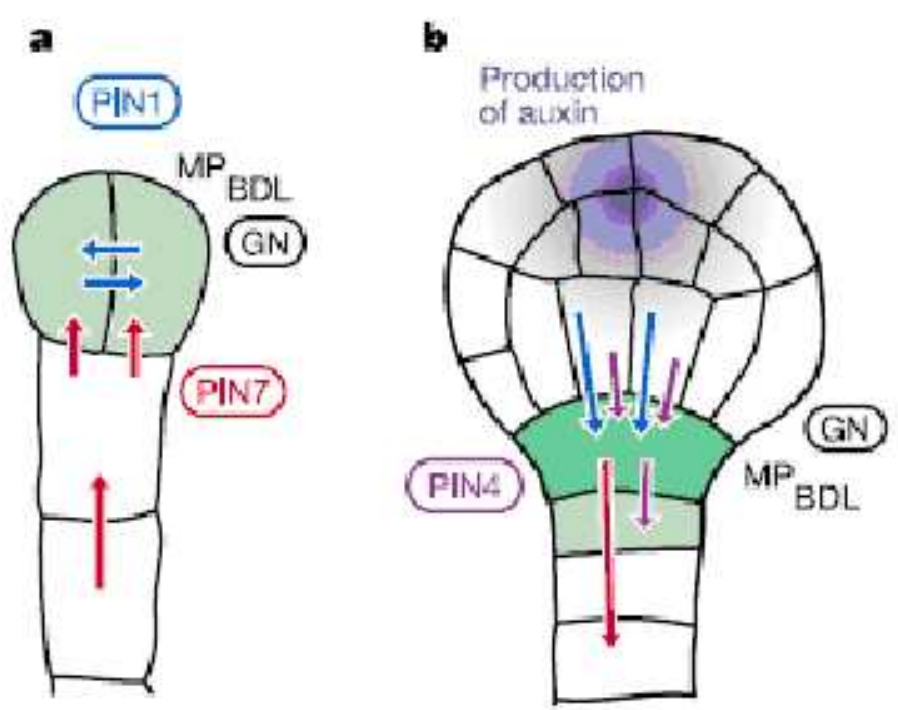

Figure 11: A model for a role of auxin in embryo patterning. Sites of auxin response and accumulation are shown in green. Arrows indicate routes of auxin efflux mediated by PIN1 (blue), PIN4 (purple) or PIN7 (red). Also depicted are proteins involved in embryo patterning and related to auxin transport (GN, encircled) or response (BDL, MP). a, Two-cell-stage embryo. Auxin accumulates in the proembryo through PIN7-dependent transport and triggers apical pole specification. b, Young globular embryo. Free auxin starts to be produced in the apical part (purple) and auxin transport routes reverse. Auxin accumulates in a PIN1- and PIN4-dependent manner in the hypophysis, triggering root pole specification (from J. Friml et al., Nature, 426 (2003), 147-153).

transport towards the region of the future root pole. Simultaneously the asymmetric localization of PIN7 is reversed within the basal cells mediating auxin transport out of the embryo. Subsequently, PIN4 expression starts at the basal pole of the embryo supporting the action of both PIN1 and PIN7 (Fig.11b). The PIN7-dependent auxin transport in the suspensor operates at a lower rate than that mediated by PIN1 and PIN4. As a result the auxin gradient reverses displaying its new maximum in the uppermost suspensor cell, which in response to auxin is specified to become the hypophysis the founder of the future root meristem.

At this stage PIN7 function becomes redundant because pin 7 mutants recovered and were able to re-establish the axis. This recovery looks similar to de novo axis formation in other auxindependent processes, such as plant regeneration from callus or postembryonic organ initiation. By contrast pin quadruple mutants failed to recover at this stage and displayed strong gnom-like defects. In the extreme case these quadruple mutants were ball-shaped entirely lacking apicalbasal polarity. The same effects were also caused by chemical inhibition of auxin transport. These findings indicate that the re-establishment of the axis at the globular stage is also mediated by a 
PIN-dependent auxin distribution and that this mechanism is probably non-redundant.

\subsection{3. “PIN-PLT" (Blilou et al., 2005)}

In this model it is also proposed that active auxin transport in the apex could generate patterned auxin distribution, thereby determining the pattern of organ formation, but the model considers the events in root apical meristem and due to that suggests the molecular mechanism different in details. Thus, it was assumed that auxin flux results from the coordinated polar localization of the auxin efflux carrier in the auxin-conducting cells. This routing of auxin is responsible for basipetal auxin transport from the young leaves towards the root. In the root tip, active polar transport generates an auxin maximum in the columella initials, which regulates meristem development and cell differentiation.

The model shows the collective contribution of five PIN genes in the control of cell division and cell expansion during root outgrowth and assess how the PLETHORA (PLT) genes, which are required for specification of the stem cell niche in roots, respond to and regulate PIN gene activity during pattern formation.

According to the model PIN proteins restrict PLT expression in the basal embryo region to initiate root primordium formation (Fig. 12a). In turn, PLT genes maintain PIN transcription, which stabilizes the position of the distal stem cell niche (Fig. 12b). At some distance from the auxin maximum PLT genes maintain PIN3 and PIN7, which reinforce acropetal auxin flux. This results in creation of an "reflux loop" that controls auxin distribution in the meristem and in the growing primordium(Fig. 12b, c). The loop stabilizes the auxin maximum and the PLT-dependent stem cell domain in the distal root tip. Moreover, it localizes meristem and cell expansion zones in the proximal meristem and regulates final cell size (Fig. 12c).

The main advantage of this work is the proving of the model by the facts that reporter genes and direct auxin measurements are consistent with the presence of a transport-regulated auxin gradient in the root meristem. Anyhow, it is possible that local auxin biosynthesis and catabolism may also contribute to the auxin concentration profile changing it considerably (Ljung et al., 2005; Kerk, $2000)$.

\subsection{4. "Protein traffic" model ( Jurdens, Geldner, 2002)}

The main idea of this model is that polar auxin flux is caused by the asymmetric distribution of its carriers within the plasma membrane. Therefore the protein traffic machinery involved in this distribution could be considered as a main player in auxin polar transport and thus in all processes mediated by auxin.

According to this model, the proteins that accumulate in specific subdomains of the plasma membrane are the following: the auxin uptake carrier AUX1 (Swarup et al., 2001), which has the apical localisation, the auxin efflux carrier PIN1 (Galweiler et al., 1998) which has the basal localisation, and COBRA, a GPI-anchored protein necessary for correct differential cell elongation with the lateral localisation (Schindelman et al., 2001). These three proteins can be found in the same cells of the Arabidopsis seedling root suggesting that targeted secretion can distinguish between 


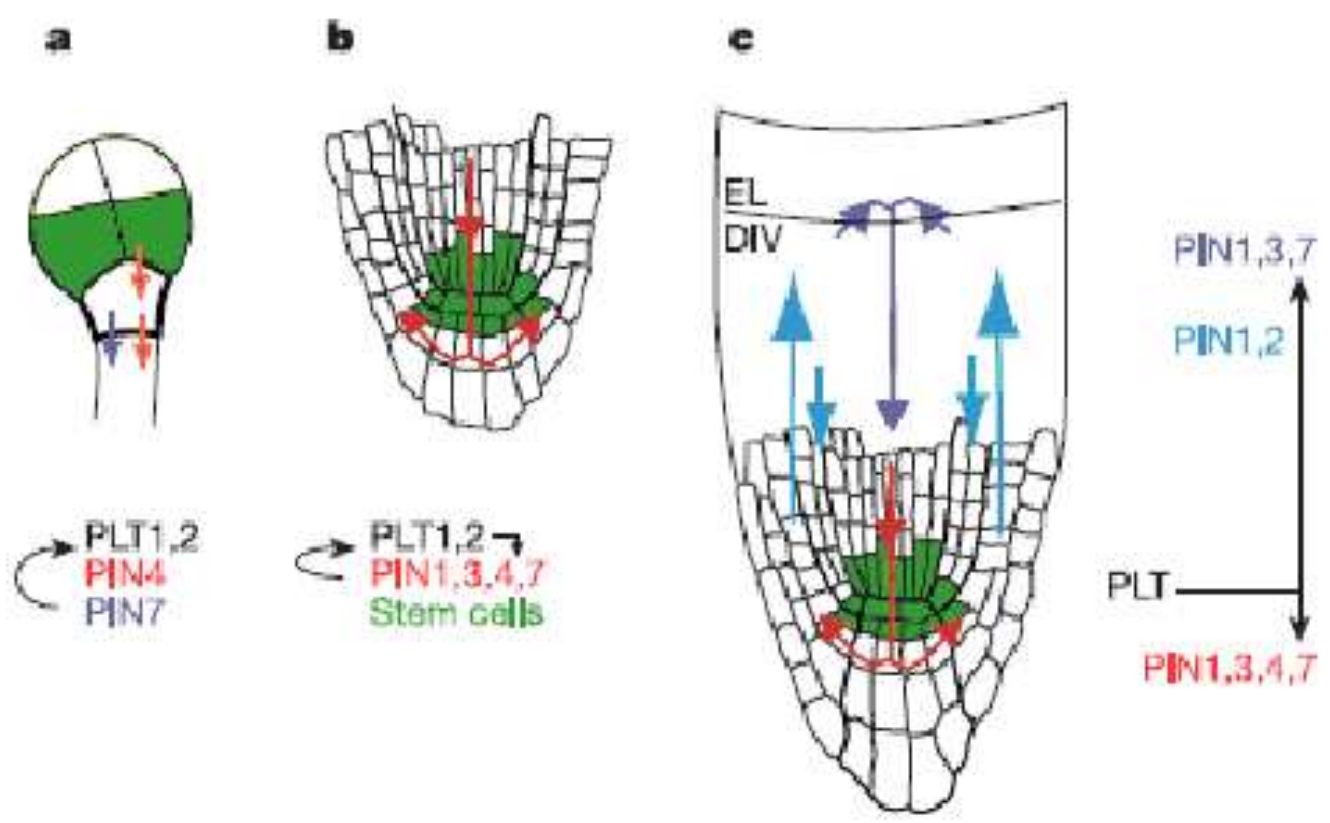

Figure 12: Model for primordium formation by PIN-PLT interactions. a. PIN-mediated rootprimordium specification by restriction of $P L T$ transcripts in octant/16-cell embryo stage. b. At later stages of embryogenesis, PIN action further restricts PLT transcripts to define the stem cell region and PLT genes start controlling root-specific PIN gene expression. c. In post-embryonic roots, $P I N$-mediated auxin transport stabilizes the stem cell region and regulates cell division (DIV) in the meristem zone and cell expansion in the elongation zone (EL). PLT genes control several members of the PIN gene family to generate primordium-specific auxin distribution (from Billou et al., Nature, 433 (2005), 39-44).

different subdomains of the plasma membrane. Other proteins localised to specific subdomains include PIN2, which accumulates at the apical end of root epidermal cells (Muller et al., 1998), and PIN3, which is predominantly observed at lateral plasma membranes of root cortical cells (Friml et al., 2002) (Fig. 13).

Targeted secretion to the apical versus baso-lateral surface of polarised cells requires sorting of proteins destined to specific subdomains within the plasma membrane and uses modified subsets of trafficking components. It has been shown that PIN1 accumulates in compartments that are distinct from adjacent Golgi stacks and most likely represent endosomes (Geldner et al., 2001). As newly synthesised PIN1 accounts only for a minor proportion of transported PIN1 protein in the cell, the determining step for the polar localisation of PIN1 should be sorting at the endosome. How sorting and targeting to the correct plasma membrane subdomain is brought about is entirely unknown. In general, vesicle budding requires small GTPases of the ARF family, their guanine-nucleotide exchange factors (ARF-GEFs) and GTPase-activating proteins (ARF-GAPs) for coat recruitment 


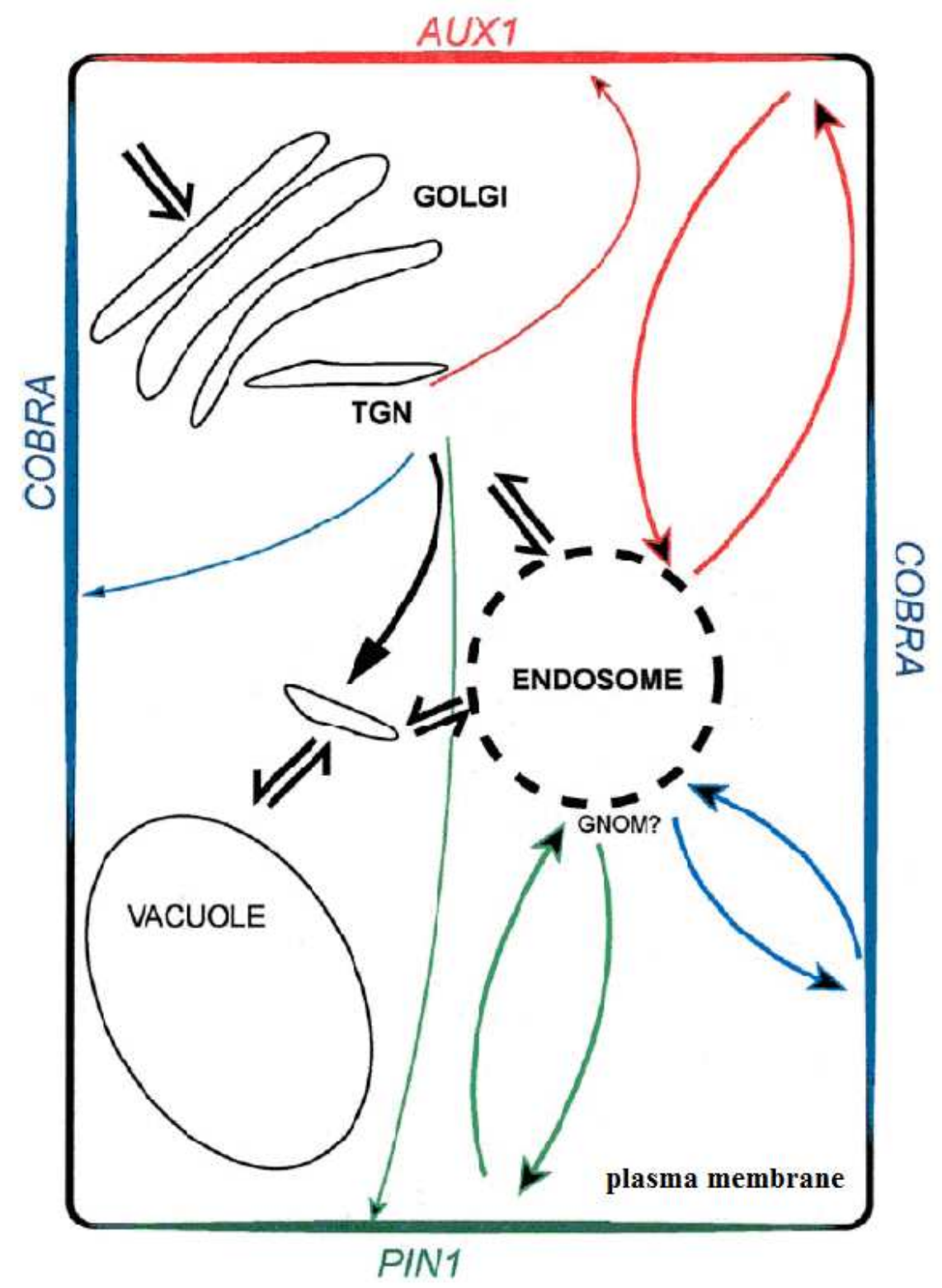

Figure 13: Model of the trafficking routes in the late secretory system in Arabidopsis root meristem cells. Plasma membrane markers (AUX1,PIN1 and COBRA) are located to distinct subdomains of the cell. Coloured arrows correspond to the possible pathways to different plasma membrane compartments from the Trans Golgi Network (TGN) and the endosome. The size of the arrows indicates the possible differences in relative contributions of these plasma membrane markers to the total protein transport in cell. (Jürgens and Geldner, Traffic, 3 (2002),605-613). 
and cargo selection. Coordinated polar localization of PIN1 develops from a random distribution in Arabidopsis early embryogenesis, but it is defective in gnom embryos, where GNOM is a membrane-associated guanine-nucleotide exchange factor (ARF GEF). Thus, GNOM might act in signal-dependent recycling of plasma membrane proteins from endosomal compartments to the cell surface establishing cell polarity resulting in polar auxin transport (Steinmann et al., 1999; Geldner et al., 2001; 2003; 2004).

In Geldner et al., (2001) it was shown that the static localization of PIN1 results from rapid actin-dependent cycling between the plasma membrane and endosomal compartments. Auxin transport inhibitors block PIN1 cycling and inhibit trafficking of membrane proteins that are unrelated to auxin transport. This data suggest that PIN1 cycling is of central importance for auxin transport and that auxin transport inhibitors affect efflux by generally interfering with membranetrafficking processes. In support of this conclusion, the vesicle-trafficking inhibitor brefeldin A (BFA) mimics physiological effects of auxin transport inhibitors.

\subsection{5. 'PIN-PGP” Model (Mravec et al., 2008)}

Recent finding showed that cellular auxin efflux depends not only on PIN but also on phosphoglycoprotein (PGP) auxin transporters. Mravec and coauthors(2008) have showed that PINs and PGPs define distinct auxin transport mechanisms: the different effects of PIN and PGP overexpression, together with the different responses of these transporters to inhibitors (NPA), clearly favors the scenario that PIN and PGP protein families define two distinct auxin efflux machineries. Both mechanisms mediate auxin efflux and components of both systems are expressed during embryogenesis, organogenesis, and tropisms but they play diverse developmental roles. The model proposed in this work states that PGP-mediated efflux controls auxin levels in auxin channel-forming cells and, thus, auxin availability for PIN-dependent vectorial auxin movement. Next the importance of the functional interaction between PIN- and PGP-dependent auxin transport in development has been analysed and it was found that a concerted action of PIN- and PGP-dependent efflux systems is required for asymmetric auxin distribution during these processes (Fig. 14).

The combined action of PIN and PGP action also determines how much auxin flows through the auxin channels. Since part of PGPs that do not colocalize with PINs acts multilaterally in auxin efflux and, thus, regulate the effective cellular auxin concentration available for PIN-mediated transport. It is likely that for long-distance transport, e.g. in stems, another mode of PGP and PIN interaction applies as suggested by strong auxin transport defects in $p g p$ mutant stems. However, different internal or external cues, for example light can influence the extent and mode of PINPGP interactions, for instance at the level of functional pairing of PINs and PGPs or by producing distinct effects on either PIN or PGP functions.

\subsection{6. "PIN-endocytosis-auxin-PLT1 model”' (Dhonukshe et al., 2008)}

The generalizing model taking into consideration although not all but most of the suggested models was recently published by Dhonukshe et al (2008). These authors have reported a model of endocytosis-dependent mechanism of PIN polarity generation and have analyzed its developmental implications. Real-time PIN tracking showed that after synthesis PINs are initially delivered 


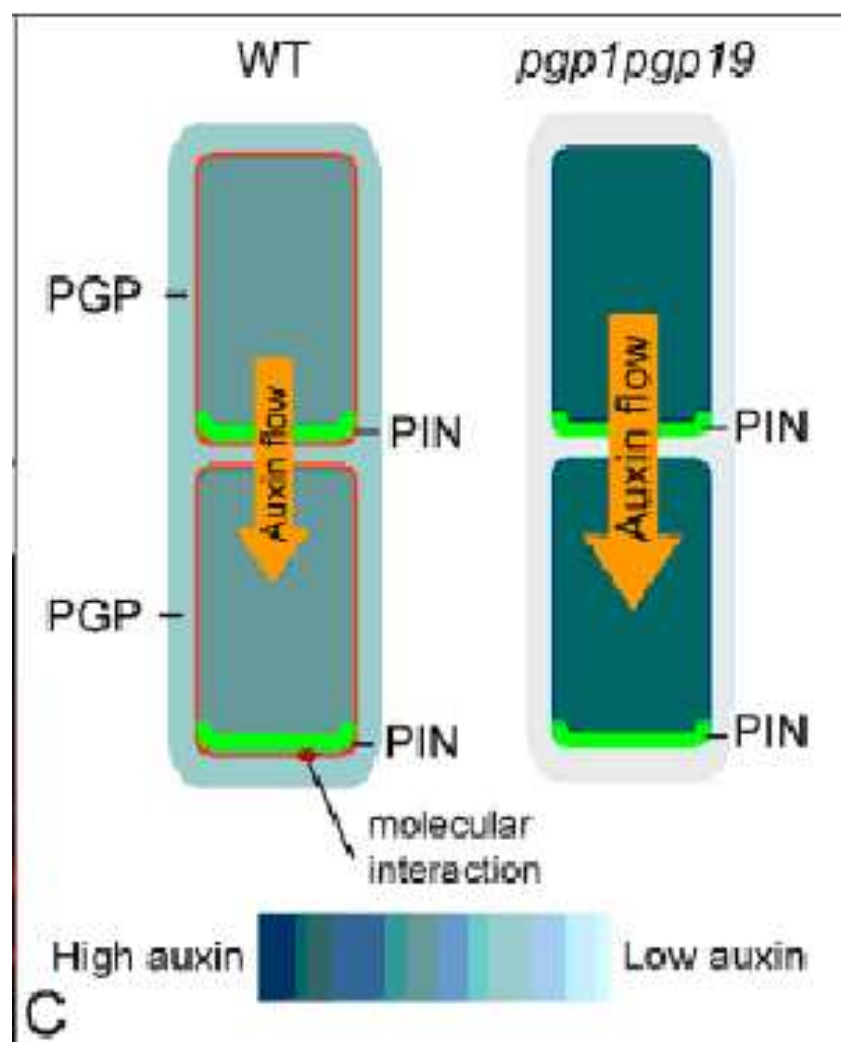

Figure 14: Model for interaction of PGPs and PINs in the local auxin distribution in meristematic tissues. PGPs and PINs interact intermoleculary at the PIN-containing polar domain, possibly regulating the PIN stability in the plasma membrane. The PGPs remaining in these cells control the cellular auxin pool available for the PIN transport. In pgplpgp19 mutant, the cellular auxin concentration is increased and, therefore, the PIN transport is enhanced but less focused (from Mravec et al., Development, 135 (2008), No. 20, 3345-3354).

to the plasma membrane in a non-polar manner and their polarity is established by subsequent endocytic recycling. The endocytic step is crucial for the polarity establishment because the interference with PIN internalization, for example by increasing auxin amounts or by manipulation with the Rab5 GTPase endocytic pathway, prevents PIN polarization and leads to polarity defects. Failure of PIN polarization transiently alters asymmetric auxin distribution during embryogenesis and increases the local auxin response in the apical embryo regions. In particular, this causes the disruption of auxin flow from developing cotyledons to the root pole, which consequently increases auxin levels at these points from auxin production, leading to the establishment of ectopic auxin response maxima at cotyledon positions. Embryonic cells are competent at this stage to interpret the increased auxin response as a positional signal for root formation and accordingly they express the root fate-promoting transcription factor PLT1 that sets up the initiation of roots at the positions of embryonic leaves. Thus the ectopic expression of auxin pathway root-forming regulator in embryonic leaves promotes homeotic transformation of leaves to roots (Fig. 15). 

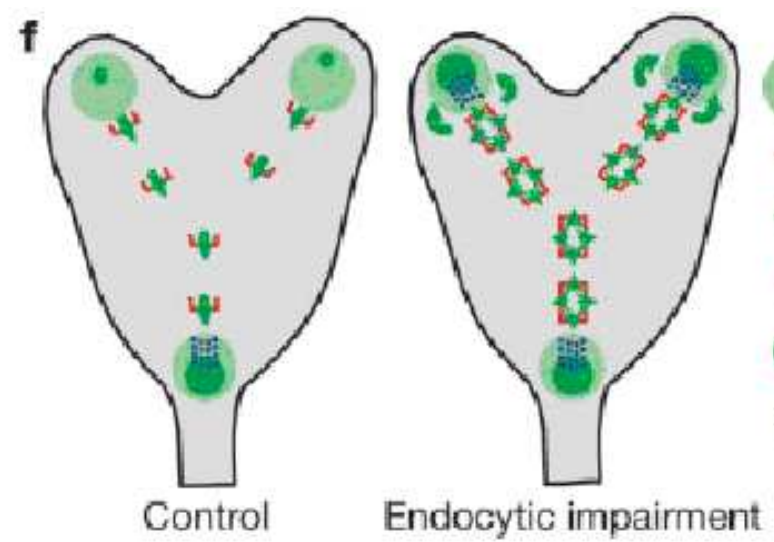

Auxin synthesis

- PIN localization

Auxin flux

- Smaller auxin response maxima

- Larger auxin response maxima

Auxin-related root-forming factor

Endocytic impairment

Figure 15: PIN-endocytosis-auxin-PLT1 Model. A schematic representation depicting enhanced auxin response maxima at the cotyledon regions resulted from non-polar PIN localization. This increased auxin response at the cotyledon regions leads to expression of auxin-induced root-forming regulators and triggers cell fate changes resulting in homeotic leaf-to-root transformation. (from Dhonukshe et al., Nature, 456 (2008), 962-966)

\section{The role of epigenetic control in plant development}

Plants are sessile organisms with the capacity to respond to a varying environment throughout their lives. Plasticity of plant growth and development is mediated through the moderation of gene expression without change to DNA sequence, a phenomenon known as epigenetics. Epigenetic mechanisms thereby mediate developmental progression of an organism and also the resilience to accommodate for change. Restriction of the totipotency in certain cells and tissues in the course of plant life is mediated by epigenetic changes as well. Thus, epigenetic regulation can be mediated in several ways, most notably by DNA methylation, histone modification and siRNA suppression, three global mechanisms regulating gene expression. DNA methylation (the addition of a methyl group to a cytosine base) in promoter region is associated with silencing of the corresponding gene in eukaryotes. Methylation occurs in the three contexts: CG, CHG (symmetric) and CHH (asymmetric). Where $\mathrm{H}=\mathrm{A}, \mathrm{T}$ or $\mathrm{C}$ nucleotide base. $\mathrm{CG}$ methylation is considered as heritable, while $\mathrm{CHG}$ and $\mathrm{CHH}$ methylations are unusually erased during meiosis and therefore are not transmitted to the next generations (Law and Jacobsen, 2010). DNA is packaged into chromatin. Histones are the core component of the chromatin. They constitute the additional level of information that affects the expression of the underlying gene. The organization of the higher order chromatin structure has been linked to post-translational modifications of histone tails, including acetylation, phosphorylation, methylation and ubiquitination. The chromatin modification within DNA region, corresponding to the certain gene or group of genes, could activate or inactivate transcription of these genes. A mechanism of gene regulation involving small interference RNA (siRNA) and microRNA (miRNA), was uncovered rather recently in both animals and plants. Their mechanism of action have been identified as sequence-specific posttranscriptional regulators of gene expression. 
siRNA and miRNA are incorporated into related RNA-induced silencing complexes, which are important for regulation of developmental programs (Tang, 2005)

The fragments of siRNA (21-24 nucleotides in length) usually suppress the expression of target gene by binding to their mRNA and then either inducing its cleavage or interfering with its translation (Bartel, 2004). In some special cases siRNA and miRNA can interfere also with transcription of given mRNA. siRNAs are alos involved in RNA-directed DNA methylation (RdDM) (Law and Jacobsen, 2010). Currently, about 100 miRNAs have been identified in Arabidopsis. Among the targets of these miRNAs, which have been experimentally confirmed, are mRNAs encoded transcription factors involved in development, such as members of the TCP, NAC, HDZIPIII, ARF, AP2 and MYB families. Mutants in which the miRNA pathway is impaired have multiple developmental abnormalities (Morel et al., 2002). Currently the role of four miRNA families during development of the shoot apex has been discovered. Thus, miR172 family is involved in the control of flowering time and floral organ identity (Aukerman and Sakai, 2003), miRNA-JAWregulates cell proliferation in the growing leaf (Palatnik et al., 2003), and MiR165/166 regulate the early abaxialadaxial polarisation of the leaf (Rhoades et al., 2002). miRNAs also play role in the formation of organ boundaries in shoot apical meristem (Laufs et al., 2004). For example, miR164 was predicted and next proved to target five members of the $N A C$ family including the $C U C 1$ and $C U C 2$ genes that specify the boundary domain around primordia. It was shown that many miRNAs have precise tissue and developmental specificity of their expression, which in most cases is opposite to the expression patterns of their targets. However, miRNA-driven suppression of its corresponding targets frequently can be not complete. Flowering plants have been shown to epigenetically inactivate certain genes during seed development depending on their parental origin (so called imprinting). For example development and size of the nutritive tissue endosperm (the core of the grain in most of cereals and other angiosperms) is determined by imprinted genes MEA, FIS2 and FIE (Chaudhury et al. 1997, Grossniklaus et al. 1998). Imprinting in the endosperm is much similar to what is observed in the placenta in mammals. Phenomenon of imprinting in plants and animals have been explained by the so called parental conflict theory according to which mothers and fathers have a different interest in allocation of resources to their offspring. As a consequence it has been proposed that paternal genes promote seed growth whereas maternal genes rather reduce growth or conversely, that in the maternal genome growth promoting factors are inactivated. The conflict of transcriptional programs imprinted differently in the parental genomes thus directly relates to seed development and seed size.

\section{Concluding remarks}

In this review we outline a biological background as a necessary prerequisite for creation of the mathematical models simulating plant growth and development. Another aim of the review is to shed light on the challenges in research of plant growth and development. These are combining several intermingle layers of consideration of this problem: morphological, physiological, genetic, and molecular. Eventually mathematical models based on this knowledge might lead in future to more thorough simulation of developmental processes. We do not aim to review here a consider- 
able amount of the existing mathematical models of plant growth, which started to appear since the beginning of twentieth century. Currently these models rapidly advance in popularity as an essential trend in mathematical biology.

\section{Recommended literature}

[1] S.H. Howell. Molecular Genetics of Plant Development. Cambridge University Press, Cambridge, 2000.

[2] B. Alberts, A. Johnson, J. Lewis, M. Raff, K. Roberts, P. Walter. Molecular Biology of the Cell (5th ed.). Garland Science, New York, 2008.

[3] TA. Steeves, and IM. Sussex. Patterns in Plant Development. Cambridge University Press, New York, 1989.

\section{References}

[4] M. Aida , T. Ishida, M. Tasaka. Shoot apical meristem and cotyledon formation during Arabidopsis embryogenesis: interaction among the CUP-SHAPED COTYLEDON and SHOOT MERISTEMLESS genes.Development., 126 (1999), No. 8, 1563-1570.

[5] M. Aida, T. Vernoux, M. Furutani, J. Traas, M. Tasaka. Roles of PIN-FORMED1 and MONOPTEROS in pattern formation of the apical region of the Arabidopsis embryo. Development., 129 (2002), 3965-3974.

[6] M. Aida, M. Tasaka Morphogenesis and patterning at the organ boundaries in the higher plant shoot apex. Plant Mol. Biol., 60 (2006), No. 6, 915-928.

[7] B. Alberts, A. Johnson, J. Lewis, M. Raff, K. Roberts, P. Walter. Molecular Biology of the Cell (5th ed.). Garland Science, New York, 2008.

[8] M.J. Aukerman, and H. Sakai. Regulation of flowering time and floral organ identity by a MicroRNA and its APETALA2-like target genes. Plant Cell, 15 (2003), 2730-2741.

[9] D.P. Bartel.MicroRNAs: genomics, biogenesis, mechanism, and function. Cell, 116 (2004), 281-297.

[10] M.K. Barton, R.S. Poethig. Formation of the shoot apical meristem in Arabidopsis thaliana an analysis of development in the wild type and in the shoot meristemless mutant. Development, 119 (1993), 823-831.

[11] T.B. Batygina. Embryoidogeny. In: T.B. Batygina [ed.], Embryology of flowering plants. Terminology and concepts.vol.2, 502-509. Science Publishers, Inc., Enfield (NH), Plymouth, 2006.

[12] T.B. Batygina, V.E. Vasileva. Plant reproduction. Sankt-Petersburg University Press, SanktPetersburg, 2002. (In Russian).

[13] E. Benkova, M. Michniewicz, M. Sauer, T. Teichmann, D. Seifertova, G. Jürgens, J. Friml. Local, efflux-dependent auxin gradients as a common module for plant organ formation. Cell, 115 (2003), 591-602. 
[14] M.J. Bennett, A. Marchant, H.G. Green, S.T. May, S.P. Ward, P.A. Millner, A.R. Walker, B. Schulz, K.A. Feldmann. Arabidopsis AUX1 gene: a permease-like regulator of root gravitropism. Science, 273 (1996), 948-950.

[15] T. Berleth, G. Jurgens. The role of monopteros gene in organizing the basal body regionof the Arabidopsis embryo. Development, 118 (1993), 575-587.

[16] N. Bessonov, N. Morozova, V. Volpert. Modeling of branching patterns in plants.Bull Math Biol., Apr;70 (2008), No. 3,868-893

[17] I. Blilou, J. Xu, M. Wildwater, V. Willemsen, I. Paponov, J. Friml, R. Heidstra, M. Aida, K., K. Palme, B. Scheres. The PIN auxin efflux facilitator network controls growth and patterning in Arabidopsis roots. Nature, 433 (2005), 39-44.

[18] W. Bloom. Cellular differentiation and tissue culture. Physiol. Rev., 17 (1937), 589-617.

[19] N.H. Boke. Leaf and areole development in Coryphantha. Am. J. Bot. 39 (1952), 134-145.

[20] L. Borisjuk, H. Rolletschek, U. Wobus, H. Weber. Differentiation of legume cotyledons as related to metabolic gradients and assimilate transport into seeds. J. Exp. Biol., 54 (2003), 503-512.

[21] E. Boucheron, A. Guivarc'h, A. Azmi, W. Dewitte, H. Van Onckelen, D. Chriqui. Competency of Nicotiana tabacum L. stem tissues to dedifferentiate is associated with differential levels of cell cycle gene expression and endogenous cytokinins. Planta, 215 (2002), 267-278.

[22] J.L. Bowman, D.R. Smyth, E.M. Meyerowitz. Genetic interactions among floral homeotic genes of Arabidopsis. Development, 112 (1991), 1-20.

[23] U. Brand, J.C. Fletcher, M. Hobe, E.M. Meyerowitz, R. Simon. Dependence of stem cell fate in Arabidopsis on a feedback loop regulated by CLV3 activity. Science, 289 (2000), 617-619.

[24] V.B. Brukhin. Paeonia embryo development in vivo and in vitro. $\mathrm{PhD}$ thesis, Komarov Botanical Institute, Russian Academy of Sciences, St.Petersburg, 1993.

[25] V.B. Brukhin, T.B. Batygina. Embryo culture and somatic embryogenesis in culture of Paeonia anomala L. Phytomorphology, 44 (1994), No. 3\&4, 151-157.

[26] M.E. Byrne, C.A. Kidner and R.A. Martienssen. Plant stem cells: divergent pathways and common themes in shoots and roots. Current Opinion in Genetics and Development, 13 (2003), 551-557.

[27] I. Casimiro, A. Marchant, R.P. Bhalerao, T. Beeckman, S. Dhooge, R. Swarup, N. Graham, D. Inze, G. Sandberg, P.J. Casero, M. Bennett. Auxin transport promotes Arabidopsis lateral root initiation. Plant Cell, 13 (2001), 843-852.

[28] A.M. Chaudhury, L. Ming, C. Miller, S. Craig, E.S. Dennis and W.J. Peacock. Fertilisationindependent seed development in Arabidopsis thaliana. Proc Natl Acad Sci USA, 94 (1997), 4223-4228.

[29] S.E. Clark, R.W. Williams, E.M. Meyerowitz. The CLAVATA1 gene encodes a putative receptor kinase that controls shoot and floral meristem size in Arabidopsis. Cell, 89 (1997), 575585.

[30] F.A. Clowes. Apical Meristems. Davis Company, Philadelphia, 1961. 
[31] JM. Cock and S. McCormick. A Large Family of Genes That Share Homology with CLAVATA3. Plant Physiology, 126 (2001), 939-942.

[32] D.J. Cosgrove. Loosening of plant cell walls by expansins. Nature, 407 (2000), 321-326.

[33] A. Delisle. The influence of auxin on secondary branching in two species of aster. Am. J. Bot., 24 (1937), 159-167.

[34] P. Dhonukshe, H. Tanaka, T. Goh, K. Ebine, AP. M?h?nen, K. Prasad, I. Blilou I.N. Geldner, J. Xu, T. Uemura, J. Chory, T. Ueda, A. Nakano, B. Scheres, J. Friml. Generation of cell polarity in plants links endocytosis, auxin distribution and cell fate decisions. Nature, 18 (2008), No. 456, 962-966.

[35] S.J. Elledge. Cell Cycle Checkpoints: Preventing an Identity Crisis. Science, 274 (1996), 1664-1672.

[36] K. Endrizzi,B. Moussian,A. Haecker,JZ. Levin,T. Laux. The SHOOT MERISTEMLESS gene is required for maintenance of undifferentiated cells in Arabidopsis shoot and floral meristems and acts at a different regulatory level than the meristem genes WUSCHEL and ZWILLE. Plant J., 10 (1996), 967-979.

[37] G.I. Evan, K.H. Vousden. Proliferation, cell cycle and apoptosis in cancer. Nature, 411 (2001), 342-348.

[38] A.J. Fleming, S. McQueen-Mason,T. Mandel and C. Kuhlemeier. Induction of leaf primordia by the cell wall protein expansion. Science, 276, (1997), 1415-1418.

[39] A.J. Fleming. Formation of primordia and phyllotaxy. Curr. Opin. Plant Biol., 8, (2005), 53-58.

[40] J.C. Fletcher, U. Brand, M.P. Running, R. Simon, E.M. Meyerowitz. Signaling of cell fate decisions by CLAVATA3 in Arabidopsis shoot meristems. Science, 283 (1999), 1911-1914.

[41] J.C. Fletcher. Shoot and Floral Meristem Maintenance in Arabidopsis. Annu. Rev. Plant Biol., 53 (2002), 45-66.

[42] J. Friml, E. Benkova, I. Blilou, J. Wisniewska, T. Hamann, K. Ljung, S., Woody, G. Sandberg,B. Scheres, G. Jurgens, K. Palme. AtPIN4 mediates sink-driven auxin gradients and root patterning in Arabidopsis. Cell, 108 (2002), No. 5, 661-673.

[43] J. Friml, A. Vieten, M. Sauer, D. Weijers, H. Schwarz, T. Hamann, R. Offringa, and G. Jurgens. Effluxdependent auxin gradients establish the apical-basal axis of Arabidopsis. Nature, 426 (2003), 147-153.

[44] L. Galweiler, C. Guan, A. Muller, E. Wisman, K. Mendgen, A. Yephremov, K. Palme. Regulation of polar auxin transport by AtPIN1 in Arabidopsis vascular tissue. Science, 282 (1998), 2226-2230.

[45] N. Geldner, J. Friml, Y.D. Stierhof, G. Jurgens, and K. Palme. Auxin transport inhibitors block PIN1 cycling and vesicle trafficking. Nature, 413 (2001), 425-428.

[46] N. Geldner, N. Anders, H. Wolters, J. Keicher, W. Kornberger, P. Muller, A. Delbarre, T. Ueda, A. Nakano, G. Jürgens. The Arabidopsis GNOM ARF-GEF mediates endosomal recycling, auxin transport, and auxin-dependent plant growth. Cell, 112 (2003), 219-230. 
[47] N. Geldner, S. Richter, A. Vieten, S. Marquardt, R.A. Torres-Ruiz, U. Mayer, G. Jürgens. Partial loss-of-function alleles reveal a role for GNOM in auxin transport-related, post-embryonic development of Arabidopsis. Development, 131 (2004), No. 2, 389-400.

[48] G. Grafi .How cells dedifferentiate: a lesson from plants. Dev Biol., 268 (2004), No. 1, 1-6.

[49] T. Greb, O. Clarenz, E. Schafer , D. Muller, R. Herrero, G. Schmitz, K. Theres . Molecular analysis of the LATERAL SUPPRESSOR gene in Arabidopsis reveals a conserved control mechanism for axillary meristem formation. Genes Dev., 17 (2003), No. 9, 1175-1187.

[50] U. Grossniklaus, J.P. Vielle-Calzada, M.A. Hoeppner, W.B. Gagliano. Maternal control of embryogenesis by MEDEA, a Polycomb-group gene in Arabidopsis. Science 280 (1998), 446-450.

[51] M.G. Heisler, C. Ohno, P. Das, P. Sieber, G.V. Reddy, J.A. Long, E.M. Meyerowitz. Patterns of auxin transport and gene expression during primordium development revealed by live imaging of the Arabidopsis inflorescence meristem. Curr. Biol., 15 (2005), 1899-1911.

[52] T. Hamann, E. Benkova, I. Baurle, M. Kientz, G. Jurgens. The Arabidopsis BODENLOS gene encodes an auxin response protein inhibiting MONOPTEROS-mediated embryo patterning. Genes Dev., 16 (2002), 1610-1615.

[53] T. Hamann, U. Mayer, G. Jurgens. The auxin-insensitive bodenlos mutation affects primary root formation and apical-basal patterning in the Arabidopsis embryo. Development, 126 (1999), 1387-1395.

[54] D. Hanahan, RA. Weinberg.The hallmarks of cancer. Cell, 100 (2000), 57-70.

[55] C.S. Hardtke, T. Berleth. The Arabidopsis gene MONOPTEROS encodes a transcription factor mediating embryo axis formation and vascular development. EMBO J., 17 (1998), 14051411.

[56] Y. Helariutta, H. Fukaki, J. Wysocka-Diller, K. Nakajima, J. Jung, G. Sena, M.T. Hauser, P.N. Benfey. The SHORT-ROOT gene controls radial patterning of the Arabidopsis root through radial signaling. Cell, 101 (2000), 555-567.

[57] S. Herwig, M. Strauss. The retinoblastoma protein: a master regulator of cell cycle, differentiation and apoptosis. Eur J Biochem., 246 (1997), No. 3, 581-601.

[58] S.H. Howell. Molecular Genetics of Plant Development. Cambridge University Press, Cambridge, 2000.

[59] K. Himanen, E. Boucheron, S. Vanneste, J. de Almeida Engler, D. Inze, T. Beeckman. Auxinmediated cell cycle activation during early lateral root initiation. Plant Cell, 14 (2002), 2339-2351.

[60] D. Jackson, B. Veit, S. Hake. Expression of maize KNOTTED1 related homeobox genes in the shoot apical meristem predicts patterns of morphogenesis in the vegetative shoot. Development, 120 (1994), 405-413.

[61] R.V. Jean. Phyllotaxis. A Systematic Study in Plant Morphogenesis. Cambridge University Press, New York, 1994.

[62] S. Jeong, A.E. Trotochaud, S.E.Clark. The Arabidopsis CLAVATA2 gene encodes a receptorlike protein required for the stability of the CLAVATA1 receptor-like kinase. Plant Cell, 11 (1999), 1925-1934. 
[63] K. Jiang, Y.L. Meng, L.J. Feldman. Quiescent center formation inmaize roots is associated with an auxin-regulated oxidizing environment. Development, 130 (2003), 1429-1438.

[64] V.M Jimenez. Regulation of in vitro somatic embryogenesis with emphasis on to the role of endogenous hormones. Rev Brasil de Fisio Vegl., 13(2001), 196-223

[65] H. Jonsson, M.G. Heisler, B.E. Shapiro, E.M. Meyerowitz, E. Mjolsness. An auxin-driven polarized transport model for phyllotaxis. Proc. Natl. Acad. Sci. USA, 103 (2006), No. 5, 1633-1638.

[66] G. Jurgens, U. Mayer, R.A.T. Ruiz, T. Berleth, and S. Misera. Genetic analysis of pattern formation in the Arabidopsis embryo. Development Suppl., 91, (1991), No. 1, 27-38

[67] G. Jurgens, N. Geldner. Protein secretion in plants: from the trans-Golgi network to the outer space.Traffic 3 (2002), No. 9, 605-613.

[68] H. Ishikawa, and M.L. Evans. Specialized zones of development in roots. Plant Physiol., 109 (1995), 725-727.

[69] N.M. Kerk, K. Jiang, L.J. Feldman. Auxin metabolism in the root apical meristem. Plant Physiol., 122 (2000), 925-932.

[70] R.A. Kerstetter, S. Hake. Shoot Meristem Formation in Vegetative Development. Plant Cell., 7 (1997), 1001-1010.

[71] A.M. Koltunow. Apomixis: embryo sacs and embryos formed without meiosis or fertilization in Ovules. Plant Cell, 5 (1993), 1425-1437.

[72] P. Laufs, A. Peaucelle, H. Morin, and J. Traas. MicroRNA regulation of the CUC genes is required for boundary size control in Arabidopsis meristems. Development, 131 (2004), 43114322.

[73] T. Laux, KFX. Mayer, J. Berger, G. Jurgens. The WUSCHEL gene is required for shoot and floral meristem integrity in Arabidopsis. Development, 122 (1996), 87-96.

[74] J. Law and S. Jacobsen. Establishing, maintaining and modifying DNA methylation patterns in plants and animals. Nature Reviews Genetics, 11 (2010), 204-220.

[75] M. Lenhard, T. Laux. Stem cell homeostasis in the Arabidopsis shoot meristem is regulated by intercellular movement of CLAVATA3 and its sequestration by CLAVATA1. Development, 130 (2003), 3163-3173.

[76] P. Leon, J. Sheen. Sugar and hormone connections. Trends Plant Sci., 8 (2003), No. 3, 110-116.

[77] C. Lincoln, J. Long, J. Yamaguchi, K. Serikawa, and S. Hake. A knottedl-like Homeobox Gene in Arabidopsis Is Expressed in the Vegetative Meristem and Dramatically Alters Leaf Morphology When Overexpressed in Transgenic Plants. Plant Cell, 6 (1994), 1859-1876.

[78] Y. Liu and M.S. Rao.Transdifferentiation-fact or artifact. J. Cell. Biochem., 88 (2003), $29-40$.

[79] K. Ljung, AK. Hull, J. Celenza, M. Yamada, M. Estelle, J. Normanly, G. Sandberg. Sites and regulation of auxin biosynthesis in Arabidopsis roots. Plant Cell, 4 (2005), 1090-104. 
[80] J.A. Long, E.I. Moan, J.I. Medford, M.K. Barton. A member of the KNOTTED class of homeodomain proteins encoded by the STM gene of Arabidopsis. Nature, 379 (1996), 66-69.

[81] J.U. Lohmann, R.L. Hong, M. Hobe, M.A. Busch, F. Parcy, R. Simon, D. Weigel. A Molecular Link between Stem Cell Regulation and Floral Patterning in Arabidopsis. Cell 105 (2001), 793803.

[82] J. Lopez-Bucio, E. Hernandez-Abreu, L. Sanchez-Calderon, MF. Nieto-Jacobo, J. Simpson, L. Herrera-Estrella. Phosphate availability alters architecture and causes changes in hormone sensitivity in the Arabidopsis root system. Plant Physiol., 129 (2002), 244-256.

[83] S. Lorenz, S. Tintelnot, R. Reski, E.L. Decker. Cyclin D-knockout uncouples developmental progression from sugar availability.Plant Mol. Biol., 53 (2003), 227-236.

[84] P. Lu,R. Porat, J.A. Nadeau and S.D. O'Neill. Identification of a meristem L1 layer-specific gene in Arabidopsis that is expressed during embryonic pattern formation and defines a new class of homebox genes. Plant Cell, 8 (1996), 2155-2168.

[85] J. Luck and H. Luck. Classification of Plant Meristems based on Cellworks (3D L-systems). The Maintainance and Comlexity of Their Cellular Patterns. In: Pattern Formation in Biology, Vision and Dynamics. Editors: A. Carbone, M. Gromov, P. Prusinkiewicz. 2000, 199-216.

[86] W. Lukowitz, U. Mayer, and G. Jürgens. Cytokinesis in the Arabidopsis embryo involves the syntaxin-related KNOLLE gene product. Cell, 84 (1996), 61-71.

[87] R.F. Lyndon. The Shoot Apical Meristem. Cambridge University Press, Cambridge. 1998.

[88] K. Lynn, A. Fernandez, M. Aida, J. Sedbrook, M. Tasaka, P. Masson, and MK. Barton. The PINHEAD/ZWILLE gene acts pleiotropically in Arabidopsis development and has overlapping functions with the ARGONAUTE1 gene. Development, 126 (1999), 469-481.

[89] Z. Magyar, L. De Veylder, A. Atanassova, L. Bako, D. Inze, L. Bogre. The role of the Arabidopsis E2FB transcription factor in regulating auxin-dependent cell division. Plant Cell, 9 (2005), 2527-2541.

[90] U. Mayer, G. Buettner, and G. Jürgens. Apical-basal pattern formation in the Arabidopsis embryo studies on the role of the gnom gene. Development, 117 (1993), 149-162.

[91] K.F. Mayer, H. Schoof, A. Haecker, M. Lenhard, G. Jürgens, T. Laux. Role of WUSCHEL in Regulating Stem Cell Fate in the Arabidopsis Shoot Meristem. Cell, 95 (1998), 805-815.

[92] R.D. Meicenheimer. Changes in Epilobium phyllotaxy induced by N-1-naphthylphthalamic acid and a-4-chlorophenoxyisobutyric acid. Am. J. Bot., 68 (1981), 1139-1154.

[93] Y. Mizukami, and H. Ma.Determination of Arabidopsis Floral Meristem identity by Agamous . The Plant Cell, 9 (1997), 393-408.

[94] A.P. Mordhorst, K.J. Voerman, M.V. Hartog, E.A. Meijer, J. van Went, M. Koornneef, S.C. de Vries. Somatic embryogenesis in Arabidopsis thaliana is facilitated by mutations in genes repressing meristematic cell divisions. Genetics, 149 (1998), 549-563.

[95] J.B. Morel, C. Godon, P. Mourrain, C. Beclin, S. Boutet, F. Feuerbach, F. Proux, H. Vaucheret. Fertile hypomorphic ARGONAUTE (agol) mutants impaired in post-transcriptional gene silencing and virus resistance. Plant Cell, 14 (2002), 629-639. 
[96] J. Mravec, M. Kubes, A. Bielach, V. Gaykova, J. Petr?sek, P. Skupa, S. Chand, E. Benkov, E. Zaz?malov, J. Friml. Interaction of PIN and PGP transport mechanisms in auxin distributiondependent development.Development, 20 (2008), 3345-3354.

[97] A. Muller, C. Guan, L. Gälweiler, P. Tänzler, P. Huijser, A. Marchant, G. Parry, M. Bennett, E. Wisman, K. Palme. AtPIN2 defines a locus of Arabidopsis for root gravitropism control. EMBO J., 17 (1998), No. 23, 6903-6911.

[98] K. Nakajima, G. Sena, T. Nawy, PN. Benfey. Intercellular movement of the putative transcription factor SHR in root patterning. Nature, 413 (2001), 307-311.

[99] D.M. Nelson, X. Ye, C. Hall, H. Santos, T. Ma, GD. Kao, TJ. Yen, J.W. Harper, P.D. Adams. Coupling of DNA synthesis and histone synthesis in $S$ phase independent of cyclin/cdk2 activity. Mol. Cell. Biol., 22 (2002), No. 21, 7459-7472.

[100] E.A. Nigg. Cyclin-dependent protein kinases: key regulators of the eukaryotic cell cycle. Bioessays, 17 (1995), No. 6, 471-480.

[101] S.J. Odelberg. Inducing cellular dedifferentiation: a potential method for enhancing endogenous regeneration in mammals. Semin. Cell Dev. Biol., 13 (2002), 335-343.

[102] K. Okada, J. Ueda, M.K. Komaki, C.J. Bell, Y. Shimura. Requirement of the auxin polar transport system in early stages of arabidopsis floral bud formation. Plant Cell 3, (1991), 677-684.

[103] D.J. Osborne, MT. McManus. Hormones, Signals and Target Cells in Plant Development. Cambridge University Press, Cambridge, 2005.

[104] J.F. Palatnik, E. Allen, X. Wu, C. Schommer, R. Schwab, J.C. Carrington, and D. Weigel. Control of leaf morphogenesis by microRNAs. Nature, 425 (2003), 257-263.

[105] S. Pien, J. Wyrzykowska, S. McQueen-Mason, C. Smart, A. Fleming. Local expression of expansion induces the entire process of leaf development and modifies leaf shape. Proc. Natl. Acad. Sci.USA, 98 (2001), 11812-11817.

[106] R.S. Poethig, E.H.J. Coe and MM. Johri. Cell linage patterns in maize Zea mays embryogenesis a clonal analysis.Dev. Biol., 117 (1986), 392-404.

[107] M.S. Rajeevan, A. Lang. Flower-bud formation in explants of photoperiodic and day-neutral Nicotiana biotypes and its bearing on the regulation of flower formation. Proc. Natl. Acad. Sci. USA, 90 (1993), No. 10, 4636-4640.

[108] D. Reinhardt. Regulation of phyllotaxis. Int. J. Dev. Biol., 49 (2005), 539-546.

[109] D. Reinhardt, F. Wittwer, T. Mandel, C. Kuhlemeier. Localized upregulation of a new expansion gene predicts the site of leaf formation in the tomato meristem. Plant Cell, 10 (1998), 1427-1437.

[110] D. Reinhardt, T. Mandel, C. Kuhlemeier. Auxin regulates the initiation and radial position of plant lateral organs. Plant Cell, 12 (2000), 507-518.

[111] D. Reinhardt, E.R. Pesce, P. Stieger, T. Mandel, K. Baltensperger, M. Bennett, J. Traas, J. Friml, C. Kuhlemeier. Regulation of phyllotaxis by polar auxin transport. Nature, 462 (2003), 255-260. 
[112] P.B. de Reuille, I. Bohn-Courseau, C. Godin, J. Traas. A protocol to analyse cellular dynamics during plant development. Plant J., 6 (2005), 1045-1053.

[113] M.W. Rhoades, B.J. Reinhart, L.P. Lim, C.B. Burge, B. Bartel and DP. Bartel. Prediction of plant microRNA targets. Cell, 110 (2002), 513-520.

[114] E. Rojo, V.K. Sharma, V. Kovaleva, N.V. Raikhel, J.C. Fletcher. CLV3 is localized to the extracellular space, where it activates the Arabidopsis CLAVATA stem cell signaling pathway. Plant Cell, 14 (2002), 969-977.

[115] E. Rosche, D. Blackmore, M. Tegeder, T. Richardson, H. Schroeder, T.J. Higgins, W.B. Frommer, C.E. Offler, J.W. Patrick. Seed-specific overexpression of a potato sucrose transporter increases sucrose uptake and growth rates of developing pea cotyledons. Plant J., 30 (2002), No. 2, 165-175.

[116] S. Sabatini, D. Beis, H. Wolkenfelt, J. Murfett, T. Guilfoyle, J. Malamy, P. Benfey, O. Leyser, N. Bechtold, P. Weisbeek, B. Scheres. An auxindependent distal organizer of pattern and polarity in the Arabidopsis root. Cell, 99 (1999), 463-472.

[117] S. Sabatini, R. Heidstra, M. Wildwater, B. Scheres. SCARECROW is involved in positioning the stem cell niche in the Arabidopsis root meristem. Genes Dev., 17 (2003), 354-358.

[118] B. Scheres, H. Wolkenfelt, V. Willemsen, M. Terlouw, E. Lawson, C. Dean, and Weisbeek, P. Embryonic origin of the Arabidopsis primary root and root meristem initials. Development, 120 (1994), No. 9, 2475-2487.

[119] G. Schindelman, A. Morikami, J. Jung, TI. Baskin, NC. Carpita, P. Derbyshire, MC. McCann, PN. Benfey. COBRA encodes a putative GPI-anchored protein, which is polarly localized and necessary for oriented cell expansion in Arabidopsis. Genes Dev., 15 (2001), No. 9, 11151127.

[120] H. Schoof, M. Lenhard, A. Haecker, K.F. Mayer, G. Jurgens, T. Laux. The stem cell population of Arabidopsis shoot meristems in maintained by a regulatory loop between the CLAVATA and WUSCHEL genes. Cell, 100 (2000), 635-644.

[121] C.J. Sherr. Cancer cell cycles. Science, 274 (1996), 1672-1677.

[122] F. Sitbon, C. Astot, A. Edlund, A. Crozier, G. Sandberg. The relative importance of tryptophan-dependent and tryptophan-independent biosynthesis of indole-3-acetic acid in tobacco during vegetative growth. Planta, 211 (2000), 715-721.

[123] F. Skoog. Chemical regulation of growth in plants. In: E.J. Boell (Ed.), Dynamics of Growth Process. 1954, 148-182.

[124] F. Skoog, C.O. Miller. Chemical regulation of growth and organ formation in plant tissues cultured in vitro. Symp. Soc. Exp. Biol., 11 (1957), 118-140.

[125] R.S. Smith, S. Guyomarch, T. Mandel, D. Reinhardt, C. Kuhlemeier, P. Prusinkiewicz. A plausible model of phyllotaxis. Proc. Natl. Acad. Sci. USA, 103 (2006), No. 5, 1301-1306.

[126] R. Soni, J.P. Carmichael, Z.H. Shah, J.A. Murray. A family of cyclin D homologs from plants differentially controlled by growth regulators and containing the conserved retinoblastoma protein interaction motif. Plant Cell, 7 (1995), No. 1, 85-103. 
[127] E. Souer, A. van Houwelingen, D. Kloos, J. Mol and R. Koes. The NO APICAL MERISTEM gene of petunia is required for pattern formation in embryos and flowers and is expressed at meristem and primordia boundaries. Cell, 85 (1996), 159-170.

[128] T.A. Steeves and I.M. Sussex. Patterns in Plant Development, Cambridge University Press, New York, 1989.

[129] T. Steinmann, N. Geldner, M. Grebe, S. Mangold , C.L. Jackson, S. Paris , L. G?lweiler , K. Palme, G. Jurgens. Coordinated polar localization of auxin efflux carrier PIN1 by GNOM ARF GEF. Science, 286 (1999), 316-318.

[130] P.A. Stieger, D. Reinhardt, C. Kuhlemeier. The auxin influx carrier is essential for correct leaf positioning. Plant J., 32 (2002), 509-517.

[131] P. Stirnberg, S.P. Chatfield, HM. Leyser. AXR1 acts after lateral bud formation to inhibit lateral bud growth in Arabidopsis. Plant Physiol., 121 (1999), No. 3, 839-847.

[132] J.M. Stone, A.E. Trotochaud, J.C. Walker, S.E. Clark. Control of meristem development by CLAVATA1 receptor kinase and kinase-associated protein phosphatase interactions. Plant Physiol., 117 (1998), 1217-1225.

[133] R. Swarup, J. Friml, A. Marchant, K. Ljung, G. Sandberg, K. Palme, M. Bennett. Localization of the auxin permease AUX1 suggests two functionally distinct hormone transport pathways operate in the Arabidopsis root apex. Genes Dev., 15 (2001), 2648-2653.

[134] G. Tang. siRNA and miRNA: an insight into RISCs. Trends in Biochemical Sciences, 30 (2005), 106-114.

[135] R.L. Taylor. The foliar embryos of Malaxias paludosa. Canad. J. Bot., 45 (1967), 15531556.

[136] W.L. Teo, P. Kumar, C.J. Goh, and S. Swarup. The expression of Brostm, a KNOTTED1-like gene, marks the cell type and timing of in vitro shoot induction in Brassica oleracea. Plant Mol. Biol., 46 (2001), 567-580.

[137] K.V. Thimann, F. Skoog. Studies on the Growth Hormone of Plants: III. The Inhibiting Action of the Growth Substance on Bud Development. Proc. Natl. Acad. Sci. USA, 7 (1933), 714-716.

[138] E. Thingnaes, S. Torre, A. Ernstsen, R. Moe. Day and night temperature responses in Arabidopsis:effects on gibberellin and auxin content, cell size, morphology and flowering time. Ann. Bot.(Lond.), 92 (2003), 601-612.

[139] R.A. Torres-Ruitz, A. Lohner and G. Jurgens. The GURKE gene gene is required for normal organization of the apical region in the Arabidopsis embryo. Plant J., 10 (1996), 1005-1016.

[140] D. Tosh and J.M. Slack. How cells change their phenotype. Nat. Rev. Mol. Cell Biol., 3 (2002), 187-194.

[141] J. Traas, I. Bohn-Courseau. Cell proliferation patterns at the shoot apical meristem. Curr. Opin. Plant Biol., 8 (2005), 587-592.

[142] B.S. Treml, S. Winderl, R. Radykewicz, M. Herz, G. Schweizer, P. Hutzler, E. Glawischnig, R.A. Ruiz. The gene ENHANCER OF PINOID controls cotyledon development in the Arabidopsis embryo. Development, 139 (2005), 4063-4074. 
[143] T. Vernoux, J. Kronenberger, O. Grandjean, P. Laufs, J. Traas. PIN-FORMED 1 regulates cell fate at the periphery of the shoot apical meristem. Development, 127 (2000), 5157-5165.

[144] C.W. Vroemen, A.P. Mordhorst, C. Albrecht, M.A. Kwaaitaal, SC. de Vries. The CUPSHAPED COTYLEDON3 gene is required for boundary and shoot meristem formation in Arabidopsis. Plant Cell, 7 (2003), 1563-1577.

[145] Y. Wang, C. Liu, K Li, F. Sun, H. Hu, X. Li, Y. Zhao, C. Han, W. Zhang, Y. Duan, M. Liu. Arabidopsis EIN2 modulates stress response through abscisic acid response pathway. Plant Mol. Biol., 64 (2007), No. 6, 633-644.

[146] F.M. Watt and B.L. Hogan. Out of Eden: stem cells and their niches. Science, 287 (2000), 1427-1430.

[147] D. Weigel, G. Jürgens.Stem cells that make stems. Nature, 415 (2002), 751-754.

[148] F.W. Went. Plant growth under controlled conditions. III. Correlation between various physiological processes and growth in the tomato plant. Am. J. Bot., 31 (1944), No. 10, 597-618.

[149] A.D. Whetton and G.J. Graham. Homing and mobilization in the stem cell niche. Trends Cell Biol., 9 (1999), 233-238.

[150] I. Wilmut, N. Beaujean, P.A. de Sousa, A. Dinnyes, T.J. King, L.A. Paterson, D.N. Wells and L.E. Young. Somatic cell nuclear transfer. Nature, 419 (2002), 583-586.

[151] R.W. Williams, J.M. Wilson, E.M. Meyerowitz. A possible role for kinase-associated protein phosphatase in the Arabidopsis CLAVATA1 signaling pathway. Proc. Natl. Acad. Sci. USA, 94 (1997), 10467-10472.

[152] J. Wyrzykowska, S. Pien, W.H. Shen, AJ. Fleming.Manipulation of leaf shape by modulation of cell division. Development, 129 (2002), 957-964.

[153] J.W. Wysocka-Diller, Y. Helariutta, H. Fukaki, J.E. Malamy, P.N. Benfey. Molecular analysis of SCARECROW function reveals a radial patterning mechanism common to root and shoot. Development, 127 (2000), 595-603.

[154] M. Yamaguchi, H. Kato, S. Yoshida, S. Yamamura, H. Uchimiya, M. Umeda. Control of in vitro organogenesis by cyclin-dependent kinase activities in plants. Proc. Natl. Acad. Sci. USA, 100 (2003), No. 13, 8019-8023.

[155] J.A. Yarbrough. Anatomical and developmental studies of the foliar embryos of Bryophyllum calicinum. Amer. J. of Bot., 19 (1932), 443-453.

[156] Y.X. Zhu, P.J. Davies. The control of apical bud growth and senescence by auxin and gibberellin in genetic lines of peas. Plant Physiol., 113 (1997), 631-637. 